\title{
How success breeds success
}

\author{
Ambroise Descamps ${ }^{1,2}$, Changxia $\mathrm{Ke}^{1}$, and Lionel Page ${ }^{* 1,3}$ \\ ${ }^{1}$ School of Economics and Finance, Queensland University of \\ Technology \\ ${ }^{2}$ Oxera Consulting LLP \\ ${ }^{3}$ Economics Discipline Group, University of Technology Sydney
}

\begin{abstract}
We investigate if, and why, an initial success can trigger a string of successes. Using random variations in success in a real-effort laboratory experiment, we cleanly identify the causal effect of an early success in a competition. We confirm that an early success indeed leads to increased chances of a later success. By alternatively eliminating strategic features of the competition, we turn on and off possible mechanisms driving the effect of an early success. Standard models of dynamic contest predict a strategic effect due to asymmetric incentives between initial winners and losers. Surprisingly, we find no evidence that they can explain the positive effect of winning. Instead, we find that the effect of winning seems driven by an information revelation effect, whereby players update their beliefs about their relative strength after experiencing an initial success.

Key Words: Dynamic Contest, Momentum, Real effort, Feedback, Confidence, Experiment.

JEL Codes: D74, C91

\footnotetext{
*Descamps: School of Economics and Finance, Queensland University of Technology and Oxera Consulting LLP, descampsambroise@gmail.com. Ke: School of Economics and Finance, Queensland University of Technology, changxia.ke@qut.edu.au. Page: Economics Discipline Group, University of Technology Sydney, lionel.page@uts.edu.au (corresponding author). For detailed and constructive comments we gratefully thank Ralph Bayer, Jeff Borland, Patrick DeJarnette, Ming He, Ningbo Huang, Boon Han Koh, Steffen Huck, Alerto Salvo, Roman Sheremeta, Joseph Tao-yi Wang, Tom Wilkening, Jinging Zhang, Jun Zhang. We also benefited from comments from seminar and conference participants at the 2016 Economics and Biology of Contest Conference (QUT, Brisbane), 2016 Australia New Zealand Workshop on Experimental Economics (UQ, Brisbane), GATE Lyon Saint-Etienne, National University of Singapore, University of Amsterdam, the 2018 Asia Pacific Economic Science Association conference (Brisbane) and the Contests: Theory and Evidence 2018 Conference (UEA). The views expressed in this article are those of the authors alone.
} 


\section{Introduction}

The famous sociologist Robert Merton coined the term "Matthew effect" (1968) to describe the fact that a success often leads to a string of subsequent successes. In support of this idea, anecdotes abound of high achievers (in business, sports or academia) describing how one critical success paved the way for what they became (Robertson, 2012). However, whether success breeds success is often debated. While some empirical studies tend to support the existence of a positive effect of past winning on future performance (Malueg and Yates, 2010; Gill and Prowse, 2012; Mago, Sheremeta and Yates, 2013; Miller and Sanjurjo, 2018; Mago and Sheremeta, 2019; Gauriot and Page, 2019), ${ }^{1}$ others have found either no evidence or the opposite (Ferrall and Smith Jr, 1999; Berger and Pope, 2011; Fu, Ke and Tan, 2015). ${ }^{2}$

We investigate this question with an experiment designed to identify both whether there is a causal effect of an initial success (also called momentum effect) and, if it does exist, what are the underlying mechanisms. We use the work-horse design of a bestof-three contest with complete information, in which a pair of players compete sequentially in (maximum) three rounds through their performance in a real effort task. The outcome of each round is determined by a stochastic Tullock success function (Tullock, 1980) and a winner arises when one player is the first to win two rounds.

We find clear evidence that players perform better in the second round of a bestof-three contest after winning in the first round, than in the counterfactual situation where they would have lost. We observe an effect on performance both at the extensive margin (time spent on the task) and at the intensive margin (tasks completed per unit of time). When looking at the underlying mechanisms, we find evidence that the effect of winning seems driven by an information revelation effect. Namely, when winning may convey information about their relative strength, the momentum effect exists; whereas it disappears when winning per se does not convey this information.

Our paper makes two contributions to the study of the effect of past success on future performance. First, it provides compelling evidence that such an effect exists. One challenge faced by empirical studies investigating momentum is the endogeneity of past performance: past winners may have unobservable characteristics which

\footnotetext{
${ }^{1}$ We focus here on the possible effects of success on future performance. Another contributing factor can be the increase in resources and opportunities generated by an earlier success (Van de Rijt et al., 2014).

${ }^{2} \mathrm{~A}$ few studies have for instance suggested mechanisms which could lead to a negative momentum because laggards are more motivated to catch up (Tong and Leung, 2002; Berger and Pope, 2011; Bergerhoff and Vosen, 2015) or because contestants may choke under pressure after an initial success (Paserman, 2010). The effect of psychological pressure has however also been assumed to be greater for lagging contestants in some particular circumstances, though the evidence here is debated (Apesteguia and Palacios-Huerta, 2010; Kocher, Lenz and Sutter, 2012).
} 
are correlated with success in each period. We develop a new empirical strategy to eliminate this concern and identify cleanly the causal effect of winning in a dynamic contest. In a baseline treatment (Baseline), we use a stochastic contest success function and leverage the purely random variations in first round outcome it generates. In the first round, conditional on the winning probability, success is entirely exogenous (it is determined by a random draw). We estimate the causal effect of success by matching and comparing winners and losers with identical winning probabilities. This approach delivers a clear result: A momentum effect exists. The first-round winners are substantially more likely to win the second round (20 percentage points increase in winning probability) as a result of both an increase in the productivity and time spent on the task.

The second contribution of our study is to reshape our understanding of the possible mechanisms underlying the momentum. Until now, the debate on the nature of momentum has mostly been articulated on whether it was the result of rational behaviour ("strategic") or not ("psychological"). In the economic literature, a momentum typically arises from past success in standard game-theoretic models of contests, assuming a complete information setting and competitors with homogeneous ability. This strategic momentum emerges due to an asymmetry in incentives between past winners and losers which generates a positive effect of a contestant's initial success on later performance relative to losers (Harris and Vickers, 1987; Konrad and Kovenock, 2006; Klumpp and Polborn, 2006; Konrad and Kovenock, 2009; Fu, Lu and Pan, 2015). But, outside of standard economic explanations, a momentum arising for psychological reasons and unrelated to strategic reasoning is often mentioned under the term psychological momentum. Cohen-Zada, Krumer and Shtudiner (2017) defined psychological momentum as "the tendency for an outcome to be followed by a similar outcome not caused by any strategic incentive of the players." A substantial literature on momentum in psychology has suggested that past success can increase later performance without any reference to strategic and rational behaviour (Bandura, 1982; Iso-Ahola and Mobily, 1980; Markman and Guenther, 2007; Cohen-Zada, Krumer and Shtudiner, 2017; Miller and Sanjurjo, 2018).

We cast a new light on this debate by looking at the role of information in the emergence of momentum. According to the two main existing explanations of momentum, players' behaviour can exhibit momentum due to different sources of information. On the one hand, the strategic momentum emerges from information about the future: The expected future rewards for winning the present round. On the other hand, the psychological momentum emerges from information about the past: The success or not in the previous round. To investigate the role of information, we toggle on and 
off different features of the best-of- 3 contest which change the informational content of an early success. We replace alternatively the first or the last round of the best-ofthree contest with strategically neutral rounds (where the winner is decided by the throw of a die) to eliminate the impact of each source of information. Replacing the first round of the contest with a neutral round, we eliminate the information about a past success while keeping the information about the future reward (treatment $\mathrm{Fu}$ tureInfo). The relative positions at the beginning of round 2 are randomly determined, and hence players do not experience a success or a failure leading them to be either ahead or behind. Alternatively, replacing the last round with a neutral round, we eliminate the cost of effort in the last round which is the cause of the asymmetric incentives that results in the standard strategic momentum using backward induction (treatment PastInfo). We find no evidence of the strategic momentum predicted by traditional game-theoretic models of complete information in the FutureInfo treatment, where the first round is replaced. Instead, in contradiction with prevailing game-theoretic explanations which ignore the role of information, we find clear evidence that past information matters. We observe a momentum in the PastInfo treatment, where participants experience success in the first round (with the possible strategic momentum mechanism being switched off).

We investigate further the role of this information about a past success by considering whether the initial success plays a role in changing participants' beliefs about their relative strength. Arguably, real-world contests are never perfectly in complete information since players cannot perfectly know each other's strength (in particular as a player's strength tend to vary over time). However, this does not mean that standard models of contests with complete information are by definition irrelevant, as these models can still be useful if they provide a good enough approximation of real-world contests. For that to be the case, it must be that the effects predicted by the models with complete information exist in real contests and that whatever effects arise from belief updating must be relatively small compared to the effects predicted by the models with complete information. Our treatments FutureInfo and PastInfo are designed to test this possibility in the best possible scenario for the models with complete information by creating a contest where players are aware the other player is very close to them in terms of characteristics. Nonetheless, small differences in participants' characteristics open the possibility that information revealed through an early success or failure may still play a role in the existence of momentum. To ascertain the possible role of information updating in momentum, we design a fourth treatment, PastWinUninformative where all the information about players' performances and winning probabilities in round 1 are revealed to players. Doing so, the winning outcome of the 
round 1 does not in itself bring any additional information about the players' relative strength. Noticeably, we observe that the momentum disappears in this treatment.

The momentum we observe in the Baseline and PastInfo treatments seems therefore driven by an information revelation effect: an initial success creates a momentum through the informational content it provides to players. Even in contests where contestants are very close in strength, like in our experiment, an initial success may be perceived as containing information about the contestants' relative strength and this information influences their later performance. This result is important for our understanding of the dynamics of momentum in contest. It suggests that traditional models relying on settings in complete information may miss a critically relevant aspect of real-world contests: The fact that players progressively change their beliefs about their relative strength. In the past, deviations from the predictions of these traditional models have been interpreted as evidence in favour of "psychological" momentum. But these deviations may not necessarily be irrational, since players could strategically adapt their behaviours in contests played as games with incomplete information.

We take from these results that understanding behaviour in dynamic competitions likely requires a departure from models with complete information to models with incomplete information. Such models may be required to understand the strategic and/or behavioural mechanisms whereby the players' beliefs in their relative strength play a role in their performance. Understanding how self-confidence is shaped by past successes and, in turn, shapes future successes can potentially play an important role in understanding how identical people can end up having very different success paths.

\section{A simplified dynamic-contest}

Real-world contests are typically embedded in overarching contests whose dynamics are complex to analyse. For instance, being successful in one tender may change a firm's relative position compared to its competitors and influence its strategies in future tenders. Similarly, a successful shot in a sporting match changes the relative scores between teams and therefore their optimal strategies. To study the effect of success on future performance, we design an experiment using the best-of-three game, where the strategic articulation between the different periods is clearly specified. We present here a description of the strategic features of this game. Extended discussions and equilibrium analysis of best-of- $\mathrm{N}$ contests can be found in Konrad and Kovenock (2009) and Fu, Lu and Pan (2015).

Consider a game of complete information with players who are payoff maximising and homogeneous in terms of ability. They compete over (up to) three rounds. 
The first player winning two rounds wins a prize $V$. We denote $e_{i t}$ the effort exerted by player $i(i \in\{A ; B\})$ in round $t(t \in\{1,2,3\})$, and $c\left(e_{i t}\right)>0$ the associated cost. The winner of a round is determined according to a contest success function, which assigns a probability of success, depending on a player and his opponent's efforts $\left(e_{i t} ; e_{-i t}\right)$. Let $p_{i t}\left(e_{i t} ; e_{-i t}\right)$ be this function. Figure 1 represents the structure of such a contest. ${ }^{3}$

Figure 1: Representation of a best-of-three game.

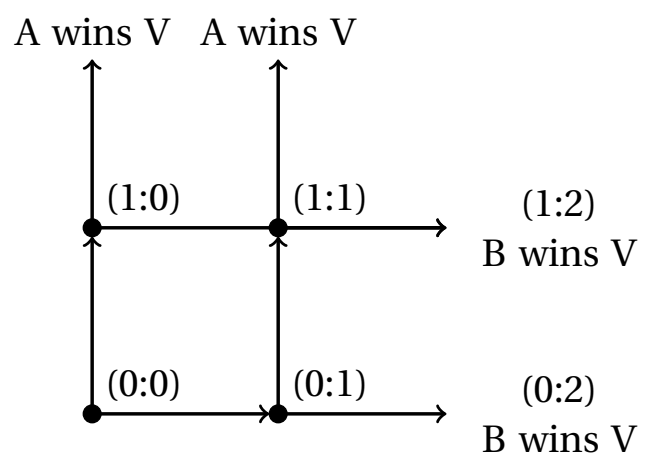

The equilibrium strategy of this game is found by backward induction. In round 3, the players face symmetric incentives. Whenever there is a symmetric equilibrium to the game (which is the case for standard contest success functions) both players will have the same expected equilibrium level of effort $e_{3}^{*}$ which induces an expected level of effort cost $c_{3}^{*}$. By symmetry, they have the same expected chance of winning the last round. In equilibrium, the expected payoff of player $i$ when reaching the third round is therefore $v_{3}=p_{i 3}\left(e_{i 3}, e_{-i 3}\right) V-c\left(e_{i 3}\right)=V / 2-c_{3}^{*}$.

In round 2, one of the two players has already won the first round. Without loss of generality, let's assume that it is player A. In case of success in round 2, A gets a value of $V$. If A is not successful he gets $v_{3}$, the expected payoff from entering the third round. In comparison, B gets a value of $v_{3}$ in case of success in the second round and 0 otherwise. The two players' incentives to exert effort only depend on the difference in expected payoffs between winning and losing in round 2 (i.e., the effective prize spread). For A, the incentive is $\delta_{A}=V-v_{3}=V / 2+c_{3}^{*}$ and for B it is $\delta_{B}=v_{3}=V / 2-c_{3}^{*}$. The incentive to exert effort is greater for the leading contestant (A), than it is for the lagging one (B): $\delta_{A}>V / 2>\delta_{B}$.

This asymmetry in incentives generates a strategic momentum effect whereby the player winning the first round expends more effort in the second round than the player

\footnotetext{
${ }^{3}$ The numbers given in brackets in Figure 1 are the score of player A versus the score of player B at each point in time. Starting from a score of 0:0 at the beginning of the contest, a player can increase his score by one after winning a round. The game ends with one of the four potential outcomes (namely, $2: 0,2: 1,1: 2$, or $0: 2$.)
} 
who has lost. Such an asymmetry has been found in a wide range of dynamic contests, leading to a similar strategic momentum effect (Konrad, 2009).

This prediction of a positive effect of success due to a variation in incentives is often opposed to another mechanism whereby the experience of success has an effect on performance via its effect on the player's mindset and confidence: "Initial success increases performers' self-confidence and sense of competence and facilitates internal attributions to ability and skills" (Iso-Ahola and Dotson, 2014). This so-called "psychological momentum", is a mechanism favoured in the psychology literature.

The notion of self-confidence which is often seen to play a role in psychology is interesting because it suggests that an initial success may change the belief of the players about their relative strength in the contest. This change of belief is not possible in models with complete information: players already know everything about themselves and the other player and they do not learn anything from winning the first round of the contest. However, real-world contests are never perfectly in complete information. Actual performance depends on skills, and preferences (e.g. preferences for winning) which are never fully observable. The notion of psychological momentum, as used in the literature, therefore possibly blends some behavioural mechanisms, which are not rationalisable, and some mechanisms which may be rationalisable, if the dynamic contest was modelled as a game of incomplete information, where players learn about their relative strength as their observe their initial results.

To further illustrate the various momentum effects, we present in Table 1 a summary of four broad types of momentum according to whether participants have complete or incomplete information and whether the momentum is driven by rational or non-rational behaviour. ${ }^{4}$ In addition to the traditional "strategic momentum" emerging from rational behaviour in games of complete information, other types of momentum could potentially exist. A non-rational momentum in contests with complete information could emerge from psychological effects which are unrelated to self-beliefs. For instance, winning the first round may lead the player to feel good or to have a positive mindset which makes the player better at performing in the second round. A non-rational momentum in games with incomplete information could also exist due to changes in behaviour following changes in self-belief. For instance, a player may feel less stressed and cooler headed when becoming more confident about his relative strength. Finally, a rational momentum could exist in games with incomplete information whereby players learn that they are better and increase their effort level as a consequence. Models of dynamic contests with incomplete information are complex and only a few studies (Konrad, 2009; Münster, 2009; Ederer, 2010; Kubitz, 2015;

\footnotetext{
${ }^{4}$ We thank a reviewer for suggesting these distinctions between four types of momentum.
} 
Table 1: The possible types of momentum, with examples of possible mechanisms.

\begin{tabular}{lcc}
\hline & Rational behaviour & Non-rational behaviour \\
\hline Contests with & Rational behaviour & Non-rational behaviour \\
complete information & in complete information & in complete information \\
& Higher incentives, higher effort & Pational behaviour \\
Contests with & Non-rational behaviour \\
incomplete information & in incomplete information & in incomplete information \\
& Higher self-confidence, higher effort & Higher self-confidence, higher effort and greater efficacy \\
\hline
\end{tabular}

Miklós-Thal and Ullrich, 2016) have provided theoretical results on such models. One of the key challenges, is that the incompleteness of information generates signalling motives. Players do not just decide their effort level to win but also to strategically change the beliefs of the other contestant. Nonetheless, we know from the models with complete information that stronger players can have the incentive to expand more effort than weaker players (Konrad and Kovenock, 2009). It is therefore not impossible that players, under incomplete information, learning that they are better after the first round would (rationally) expend more effort in the second round. The term "psychological momentum" which has been used to describe any momentum departing from the standard "strategic momentum" in complete information may actually have been used to describe behaviour which would be rational in games with incomplete information.

\section{Experimental design and implementation}

We design a best-of-3 contest experiment with the aim to have the best chance of observing the two types of momentum presented in Table 1 (i.e., the rational ("strategic") versus non-rational ("psychological”) behaviour in contests with complete information). Relative to field studies (Malueg and Yates, 2010; Gauriot and Page, 2019), we create a setting as close as possible from a contest with complete information like those investigated by game-theoretic models: players are nearly homogeneous in ability and this fact is common-knowledge among players. We also include a monetary opportunity cost of time spent on the task to ensure that effort is costly enough. We expect these features to give the best chances to generate the type of strategic momentum predicted in game theoretic model in complete information, if it exists. Relative to prior experimental studies (Mago, Sheremeta and Yates, 2013; Mago and Razzolini, 2019), our design innovates by using a real-effort task. We expect this feature to increase the external validity of the design in giving the best chances to generate 
a "psychological momentum" driven by the fact of experiencing a success after a real performance. $^{5}$

The effort task we adopted is inspired by Huck, Szech and Wenner (2015): Participants observe on their computer screen a string of 20 characters (numbers, lower and upper cases letters), and have to type backwards from the last character in a text-box below it. ${ }^{6}$ Each time a string is correctly typed in a reverse order, a new one appears on the screen (see Figure 2 for an experimental screen-shot).

The opportunity cost of time is implemented by including a "STOP" button at the bottom-right of the task screen, so that participants can quit working at any time during the competition. Each round of the contest lasts for 10 minutes and participants are endowed with $\$ 3$ in total at the beginning. For each second spent on the effort task, participants lose half a cent $(\$ 0.005)$ of their initial endowment. However, the longer they work on the task, the higher is their performance and hence the more likely they will win a prize of $\$ 20$. Introducing the opportunity cost of time, like in (Gächter, Huang and Sefton, 2016) and (Erkal, Gangadharan and Koh, 2018), avoids the problem of participants' inelastic response to incentives in real-effort experiments, found by previous literature (Araujo et al., 2016).

Figure 2: A screen-shot of the effort task faced by participants.

\section{Transcription task}

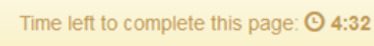

To test for the existence of the strategic momentum effect, we pair players by their abilities and inform them about the pairing to establish common-knowledge about the ability difference. It ensures that the contest environment is as close as possible to the game of complete information. Prior to the best-of-three contest, participants

\footnotetext{
${ }^{5}$ In chosen effort experiments (Mago, Sheremeta and Yates, 2013; Mago and Razzolini, 2019), players simply indicate the "effort" they are willing to expend and pay a (monetary) price for it. In this setting, prior studies have not found evidence of a "psychological" momentum. Chosen-effort experiments present the advantage of better controlling the cost faced by participants, but they base the study of momentum on a contest without a real performance.

${ }^{6}$ To avoid confusion, characters that are too similar were not included, such as capital “O” and zeros.
} 
enter an initial round where their performances at the task are measured in order for them to be paired by strength in the best-of-three contest. We call this part of the experiment the evaluation stage. A player's success in one round of the best-of-three contest is determined stochastically by the Tullock lottery success function which is most widely used in the literature (Dechenaux, Kovenock and Sheremeta, 2015). With such a function, the winning probability of player $i$ conditional on his own and opponent's effort ( $e_{i t}$ and $e_{-i t}$ respectively) in a round $t$ is:

$$
p_{i t}=\frac{e_{i t}}{e_{i t}+e_{-i t}}
$$

The lottery function introduces controlled randomness to the outcome of a round which makes it possible to cleanly identify the causal effect of winning in round 1 on the performance in round 2 .

\subsection{Treatment design and testing hypotheses}

In the Baseline treatment, we implement a standard best-of-three contest after the evaluation stage. The timing of the Baseline treatment is depicted in the top-left corner of Figure 3. After each round of the best-of-three contest, participants are informed of the winner of that round, who is randomly drawn by the computer according to their winning probabilities. Apart from this final outcome, players are not given any additional information, neither the actual number of tasks completed nor the winning probability of each player. In the real world, information is often limited to outcomes with actual levels of effort being unobserved. Our baseline experimental set up reflects such a situation. ${ }^{7}$ The Baseline treatment is designed to test whether there is any causal effect of winning at all. First, we define the causal effect of winning as follows:

Definition 1 Momentum effect. In a dynamic contest, there is a positive (negative) momentum effect of early winning on later performance if a player displays a higher (lower) performance after an initial win than in the counterfactual situation where he/she would have lost.

Given this definition of the effect of winning, our first hypothesis is the following:

Hypothesis 1 Positive momentum. A positive effect of winning will be observed in the Baseline treatment.

\footnotetext{
${ }^{7}$ Furthermore, in a game of complete information with homogeneous players, players know their and their opponents' types and observing their opponent level of effort/performance does not have any strategic value in equilibrium.
} 
Figure 3: Representation of the different experimental treatments. "P" stands for past information, and " $F$ " stands for future information.

Baseline

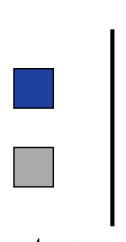

Eval. stag

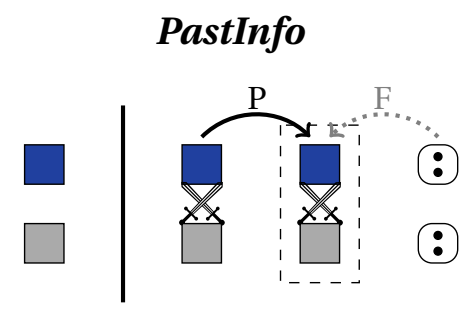

Eval. stage round 1 round 2 round 3

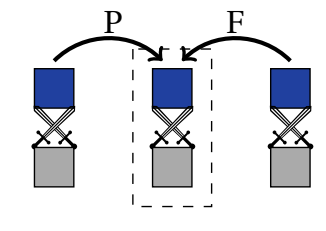

FutureInfo

round 1 round 2 round 3

nd 3

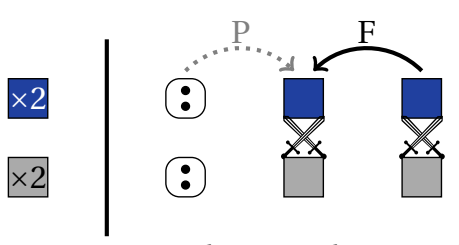

Eval. stage round 1 round 2 round 3

Player A Player B

PastWinUninformative

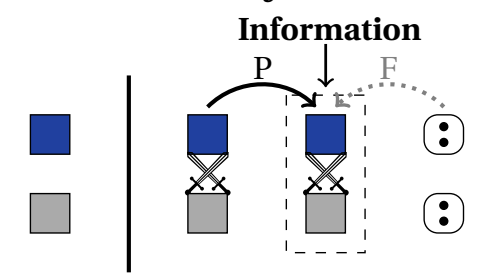

Eval. stage round 1 round 2 round 3

This hypothesis reflects the widely held idea that winning can have a positive effect on subsequent performance. However, if an effect is observed in the Baseline treatment, it is impossible to tell whether it is because players (who have anticipated the later stages of the game) form different expected gains from effort using backward induction or whether they mainly react to the fact of having won in the first round. Both explanations have the same prediction: the first-round winner performs better in the second round relative to his/her matched counterfactual.

The second treatment (FutureInfo) is designed to isolate the effect of information about the future stages of the contest. We place players randomly in either a leading or trailing position in round 2 . To do so, we assign subjects to either odd or even numbers at the start of the contest, and a computer-simulated die determines the winner in round 1. As the first round is random, it does not provide successful players with the experience of winning as a result of their own performance in round 1. Observing a causal effect of winning in FutureInfo would reveal that this effect cannot be explained primarily by the information about a prior success. Instead, this momentum would be compatible with game-theoretic models of contest, where the mere asymmetry of players' positions influence their' strategic effort decisions. ${ }^{8}$

\footnotetext{
${ }^{8}$ Note that it does not exclude every possible type of "psychological momentum". It is possible that the simple fact of being ahead has a positive effect of mindset even if it did not bring any new information to the players (see Table 1).
} 
Hypothesis 2 Effect of future information There is a positive effect of winning in FutureInfo treatment, even though the leading players do not experience an initial success that is linked to their performance.

Note that participants do not exert effort in round 1 in FutureInfo treatment. To avoid generating differences in fatigue in round 2 across different treatments, participants play two initial rounds in the evaluation stage before the best-of-three contest in FutureInfo. The pairing is similar to other treatments: only the first initial round is used as an evaluation stage to pair participants. The top right panel of Figure 3 shows the timing of this treatment.

The third treatment (PastInfo) is designed to identify the effect of past information by turning the possible effect of future information off. As mentioned in Section 2, the expected cost of effort to be expended in the third round causes an asymmetry in incentives in round 2 between round 1 winners and losers. If no effort is to be exerted in the last round, the expected value of going to the last round becomes symmetric $(\mathrm{V} / 2$ for both players). As a consequence, the round-1 winner's incentive in round 2 (i.e., $V-V / 2$ ) is the same as round-1 loser's incentive in round 2 (i.e., $V / 2-0$ ). We eliminate the cost of effort and hence the asymmetry of incentives in round 2 by selecting the winner of round 3 randomly, using the same dice procedure as in FutureInfo. The bottom left corner of Figure 3 shows the timing of the PastInfo treatment. In this scenario, if a player's performance is higher after winning (versus losing) in round 1, it cannot be attributed to standard strategic considerations. ${ }^{9}$

Hypothesis 3 Effect of past information. There is a positive effect of winning in PastInfo treatment, even though the usual asymmetry of incentives (from backward induction) between winners and losers is absent.

Finally, the fourth treatment (PastWinUninformative) extends the third treatment by turning off one possible effect of past information. A natural interpretation of the psychological effect is that players interpret success as giving them information about their relative strength compared to their opponent. We designed our experiment carefully to have matched players in terms of ability. However, it is not possible, neither in experiments, nor in real settings, to eliminate all differences between players. After the first round, players could therefore update their belief about who is the strongest among the two players. To eliminate the possible effect of success on the players' confidence in their relative strength, we modify the PastInfo treatment and display all the

\footnotetext{
${ }^{9}$ Note that the game structures of the Baseline and PastInfo are different. Players expect to play two more rounds after a win in Baseline and only one more round in PastInfo. Therefore, we do not expect an effect of past information to be necessarily equal in the Baseline and in PastInfo. But if past information has an effect, we would expect to observe an effect of winning in PastInfo.
} 
information about the round 1 performances (including time spent on the task, task completed, winning probabilities of both players) on the computer screen where the winner is revealed at the end of each round. ${ }^{10}$ By giving players all this information when round-1's winning outcome is revealed, we remove all the informational content of the outcome. Participants with a winning probability $p$ have the same information about their past performance. Therefore, winners and losers who are matched based on having the same winning probability in round 1 do not differ in their beliefs about their relative strength. Hence, there should be no information-driven effect of success in the PastWinUninformative treatment.

Hypothesis 4 Effect of past information when success is not informative. Winning per se should not have a causal effect on performance in PastWinUninformative.

If we observe a momentum effect both in PastInfo and PastWinUninformative, it would suggest that a psychological momentum exists and that it is not due to an effect on players' beliefs about their relative strength. Instead, it could be due to an effect on other aspects of the players' mindset. For instance, successful players may feel elated from their initial success and this feeling could drive a greater performance. However, if we observe a momentum effect in PastInfo but not in PastWinUninformative, it would suggest that a psychological effect that only works through positive mindset and great efficacy does not exist and the change in psychology must go through confidence changes via information updating.

\subsection{Two ability-pairing conditions}

Ability pairing is crucial in our design to form a common-knowledge of equal ability within a pair, mimicking the complete information setting of game-theoretic models. We implemented our full experimental design in the laboratory using two pairing conditions to ensure our results are robust to how participants are paired.

We first run the experiment with a pairing of participants based on their raw performance. To do so, we incentivise participants to try their best by using a piece-rate payment scheme in the initial round. This round lasts 10 minutes and each transcription task correctly completed is rewarded with 20 cents $(\$ 0.2)$. No timeout "STOP" button is available. The aim of this piece-rate round is to estimate the strength of the

\footnotetext{
${ }^{10}$ Note that the fact this information will be revealed is not announced in the experimental instructions they receive at the beginning of the contest stage, which means this information comes as a surprise to the participants at the end of round 1. This design ensures that participants have the same information/expectation in both PastInfo and PastWinUninformative treatments when they compete in round 1.
} 
players as their raw skill at the task. Pairing players on their raw skills follows closely the assumption of game-theoretic models of contest with homogeneous players.

In practice, however, we could be concerned that players may differ along other dimensions than ability. Players' performance in the contest could potentially differ significantly because of different propensities to use the "STOP" button (e.g. if they differ in "grit"). In that case, pairing players only on their raw ability would not take that heterogeneity into account. To control for this possibility, we also implement another pairing that is based on participants' performance in a single contest in the initial round. The single contest (with a prize value of $\$ 7$ ) is resolved in the same way as each round in the best-of-three contest, and a "STOP" button is available. The aim of this one-round contest is to measure the strength of the player using his performance in a single contest environment which is similar to one round of the dynamic contest. This performance derives not only from the player's raw skill at the task but also from his propensity to stop earlier in a contest. We label these different pairing conditions as "Raw-performance pairing" and "Contest-performance pairing", respectively. Overall our results are very similar across these two conditions.

Participants are then paired based on principles which are common-knowledge to them. In all experimental sessions, after the evaluation stage and before the beginning of the best-of-three contest, participants are informed that they will be placed in pairs based on their performance in the evaluation stage. The best performer in the session is paired with the second-best performer, the third is paired with the fourth, and so on. This is the only information they receive about them and their opponent. The information about the contest and the pairing is given only after the evaluation stage to ensure that participants do not play strategically in the evaluation stage. ${ }^{11}$

\subsection{Data collection}

We ran experimental sessions in two Australian universities of comparable size and student demographics. In each university, a session lasted around 75 minutes, including the time for instructions and payments and the same experimenter ran all the sessions. The experiment was programmed in oTree (Chen, Schonger and Wickens, 2016). Participants were recruited from various faculties using ORSEE (Greiner, 2015).

The sessions with raw-performance pairing condition as the evaluation stage were run at the Queensland University of Technology (QUT) in 2017: 198 students took part in 14 sessions gathering between 10 and 18 participants each. The mean age of participants was $21,54.3 \%$ were males. The number of participants per treatment was $\mathrm{N}=50$

\footnotetext{
${ }^{11}$ We follow here the approach of Fu, Ke and Tan (2015).
} 
in Baseline, $\mathrm{N}=46$ in FutureInfo, $\mathrm{N}=48$ in PastInfo, and $\mathrm{N}=54$ in PastWinUninformative. The average payment is composed of a $\$ 5$ show-up fee, and a variable earning of $\$ 15$ on average, ranging from $\$ 0$ to $\$ 34$.

The sessions with contest-performance pairing condition as an evaluation stage were run at the University of Technology Sydney (UTS) in 2019: 240 students took part in 8 sessions gathering between 22 and 40 students each. ${ }^{12}$ The mean age of participants was $24,56.7 \%$ were males. The number of participants per treatment was $\mathrm{N}=66$ in Baseline, $\mathrm{N}=58$ in FutureInfo, $\mathrm{N}=58$ in PastInfo, and $\mathrm{N}=58$ in PastWinUninformative. The average payment is composed of a $\$ 10$ show-up fee, and a variable earning of $\$ 19$ on average, ranging from $\$ 1$ to $\$ 40 .^{13}$

The participants received instructions about the initial round(s) both in written form and in PowerPoint slides presentation to ensure common-knowledge before they start the evaluation stage. Afterwards, participants were given a separate set of instructions for the best-of-three contest to read, followed by a short summary presentation. A few control questions were then displayed on their screens, testing their understanding of the game before the game started. At the end of the experiment, participants were asked a few demographic questions. We collected participants' beliefs about their chance to win the next round before each round. We use a simple nonincentivised question: "According to you, how likely are you to win the next round (in \%)?". ${ }^{14}$ In the sessions ran at UTS, we added several questions: one question about their beliefs in being the best performer within their pair in the next round and four questions to ascertain the players' ability to reason with backward induction, using games designed by Grabiszewski and Horenstein (2019).

\section{Estimation strategy}

We aim to estimate the effect of winning the first round on the performance in the second round. For simplicity, and in line with section 2's game-theoretic framework, we use "effort" as the main driver of performance in the discussion about the identification strategy. This framework easily generalises to situations where performance

\footnotetext{
${ }^{12}$ We increased the size of the session here on purpose to improve the quality of the pairing of participants by ability.

${ }^{13}$ The difference in average variable earnings between the UTS and QUT data is largely driven by the four incentivised backward-induction games added to the post-experimental questionnaire in UTS sessions. Details about these games will be provided in Section 6.1. We followed the different standards of show-up fee used by each lab which potentially reflects the higher opportunity cost of showing up on UTS campus due to longer commuting time.

${ }^{14}$ It has been shown that simply asking participants their subjective beliefs works well as an elicitation method (Hollard, Massoni and Vergnaud, 2016).
} 
can be affected by other factors, such as the effectiveness of the effort, preference for competing, and risk attitude. To model the effort $\left(e_{i t}\right)$ in each round $t$, let's consider the following model:

$$
\left\{\begin{array}{l}
e_{i 1}=\alpha+\delta_{1}+u_{i}+\varepsilon_{i 1} \\
e_{i 2}=\alpha+\beta w i n_{i 1}+\delta_{2}+u_{i}+\varepsilon_{i 2}
\end{array}\right.
$$

The variable $w i n_{i 1}$ in (2) is a dummy taking the value 1 if individual $i$ won in round 1 , and 0 otherwise. The intercept $\delta_{t}$ is a round specific element which accounts for learning or exhaustion as the participants move through the contest. The term $u_{i}$ is an individual effect which accounts for heterogeneity, such as individual differences in ability or preference for competition. Finally, $\varepsilon_{i t}$, is a round and individual specific disturbance which captures residual variations in effort in a given round for a given individual.

The model (2) has, de facto, a dynamic panel data structure since $w i n_{i 1}$ is a function of $e_{i 1}$. As a consequence, usual estimation procedures will deliver biased estimates. It is easy to see that estimating the effect of $w i n_{i 1}$ by ordinary least squares (OLS) suffers from an endogeneity problem. The individual effect $\left(u_{i}\right)$ impacts effort in the first round $\left(e_{i 1}\right)$, which, in turn, affects individual $i$ 's winning chances $\left(w i n_{i 1}\right)$. Individuals who exert more effort than their opponent in each round are more likely to win round 1 and round 2 . It creates a spurious correlation between the outcome of the two rounds.

Trying to control for this unobserved heterogeneity using a fixed-effects regression also gives biased estimates. The so-called Nickell bias arises from the fact that the fixed effects absorb part of the noises $\varepsilon_{i 2}$ (Nickell, 1981). It creates an attenuation bias which can be very large when the panel dimension is short as in our case.

Taking the first difference of equation (2) to try to directly eliminate the unobserved heterogeneity does not work either. The new estimated equation becomes:

$$
\Delta e_{i}=\beta w i n_{i 1}+\Delta \delta+\Delta \varepsilon_{i}
$$

with $\Delta e_{i}=e_{i 2}-e_{i 1}, \Delta \delta=\delta_{2}-\delta_{1}, \Delta \varepsilon_{i}=\varepsilon_{i 2}-\varepsilon_{i 1}$. The individual heterogeneity $u_{i}$ is netted out of the estimation, solving the endogeneity problem of equation (2). However, a different endogeneity problem appears. Random variations of $\varepsilon_{i 1}$ in round 1 are positively correlated with the winning probability. As a consequence there is a negative correlation between $\Delta \varepsilon_{i}$ and $w i n_{i 1}$ and the exogeneity assumption is violated for $w_{i} n_{i 1}$. We can expect a negative bias in $\widehat{\beta}$ due to a regression towards the mean. A win in round 1 partially signals a likely high $\varepsilon_{i 1}$, meaning that the effort in round 2 is not likely to be as high in round 2 due to a lower $\varepsilon_{i 2}$. 
One solution, proposed by Gill and Prowse (2014), is to use the effort of a contestant's opponent as an instrumental variable. The opponent's effort is not correlated with the contestant's effort choice and directly affects his winning chances. However, in our experiment participants are paired with each other by ability in order to closely match the hypothesis of homogeneous ability from the game-theoretic model. Effort levels are therefore highly correlated within a pair, thereby making the instrument invalid. ${ }^{15}$

We develop here a novel approach. Since we use a stochastic contest success function, the result of each round is partly random and the probability of winning of each player is perfectly determined. We therefore use this probability to match winners and losers with similar winning probabilities. ${ }^{16}$ Conditional on the winning probability the outcome of the round is purely random: it is the result of a random draw from the computer. We can therefore identify the causal effect of winning using this random variation in winning. ${ }^{17}$ To do so we match winners and losers who have similar ex-ante winning probabilities. ${ }^{18}$ We use a local linear regression matching which compares each winner to a weighted average of losers with similar probabilities (Heckman, Ichimura and Todd, 1998). More weights are given to counterfactual observations with closer matching probability. ${ }^{19}$ We use a bandwidth of $h=0.025$ in our estimations. For example, a round 1 winner with a $50 \%$ chance of winning would be compared to round 1 losers with a minimum probability of winning of $47.5 \%$ and a maximum one of $52.5 \% .^{20}$

As required in matching estimations, we implement a common support restriction suggested by Smith and Todd (2005). We keep in our sample only the set of observations where the empirical distributions of the winning chances of the winners and losers overlap. This restriction ensures that all players who won with a probability $p$

\footnotetext{
${ }^{15}$ Let's consider player $i$ and his opponent $-i$. The performance $e_{-i 1}$ of the opponent $-i$ in the first round of the contest is likely correlated with his performance in the evaluation stage $e_{-i 0}$ (due to unobserved heterogeneity $u_{-i}$ ). Given the pairing, this performance is itself correlated with the performance of the player $i$ in the evaluation stage, $e_{i 0}$. And, therefore, it is also correlated with the performance $e_{i 1}$ of the player $i$ in the first round of the contest (due to unobserved heterogeneity $u_{i}$ ).

${ }^{16}$ This approach is similar to a propensity score matching procedure (Todd, 2010), but contrary to most propensity score matching applications we perfectly know how the probability of an observation being in one or the other conditions. It is precisely determined by a function taking the observed performance of players as input. Our matching approach is therefore not threatened by the possible residual effect of unobservable characteristics on the outcome (this concern typically arises when propensity score matching is used with field data).

${ }^{17}$ Consider for example players who had $60 \%$ chances of winning the round 1 based on their performance (and the performance of their opponent) in that round. Some will be successful and some won't, due to the computer's random draw. The situations where players have a $60 \%$ chance of winning round 1 may be heterogeneous, but the win/loss result will be randomly allocated among these players.

${ }^{18}$ See Appendix B for a formal description of the matching approach.

${ }^{19}$ As shown by Fan (1992), local linear regression are also a form of local weighted averaging.

${ }^{20}$ We show that our results are robust to other choices of bandwidth in the online Appendix C.3.
} 
can be compared with players who lost with the very similar probabilities (and viceversa). ${ }^{21}$ While bootstrapping fails for nearest neighbour matching, it provides reliable standard errors in the local linear regression case (Abadie and Imbens, 2008).

In the FutureInfo treatment, where participants are randomly allocated to a win or loss outcome in round 1 with a $50 \%$ chance, the matching procedure is a degenerate case whereby each winner is compared to every loser. It is therefore equivalent to simple OLS.

\section{Main results}

\subsection{Overview of the data}

Our random allocation of participants across treatment did not lead to noticeable differences in their characteristics. ${ }^{22}$ Table 2 shows the number of strings completed correctly overall and by treatment, for each pairing condition and when pooling observations from both pairing conditions. ${ }^{23}$ The performance levels vary slightly in the evaluation stage between two pairing conditions which were run on different locations. When pooling observations across pairing conditions, participants completed on average around 16 strings in the initial round and between 17 to 22 strings in the best-of-three contests. There is no significant difference in average performance in the evaluation stage across treatments whether it is compared within each condition $(p-$ value $=0.521$ and 0.983$)$ or when all observations are pooled ( $p-$ value $=0.802)$.

After the evaluation stage, participants are paired by performance. The resulting within-pair differences of performances are fairly small. The average difference in performance within a pair is 2 when the evaluation stage is a piece-rate round and 1.15 when it is a one-round contest. It is also reassuring that there is no significant difference in average performance in the first round of the best-of-three contests across all treatments $(p-$ value $=0.824) .24$

\footnotetext{
${ }^{21}$ We report the standard errors constructed by standard bootstrap in the main text. As a robustness check, we also provide the standard errors using bootstraps at the pair-level in the online appendix to account for the non-independence of observations within pairs. Our main results are stable to the way we bootstrap standard errors.

${ }^{22}$ Table 11 in the online Appendix provide detailed statistics on the participants' demographics per treatment.

${ }^{23}$ Tables 7 and 8 in Appendix provide more detailed summary statistics.

${ }^{24}$ Note that to control for learning or fatigue (as is explained in section 3.1), participants in the $F u$ tureInfo treatment were randomly re-matched after the first round of the evaluation stage and were requested to compete in another single-round contest. The repetition came as a surprise to them because we wanted to keep everything comparable in the initial round, which we later use for ability pairing. It is also reassuring to note that the average performance in the second single-round contest in the FutureInfo treatment is 18.40 for all observations, which is very similar to the average round-1
} 
Table 2: Comparison of performances overall and by treatment and pairing conditions. Only the first round performance in the evaluation stage is presented for the FutureInfo treatment in order to have a comparable situation to other treatments. Note that, by design, the overall number of observations is the sum of observations in Baseline, PastInfo and PastWinUninformative (shorten as PastWinUn) in round 1 and the sum of observations in Baseline and FutureInfo in round 3.

\begin{tabular}{|c|c|c|c|c|c|c|c|}
\hline \multirow[b]{2}{*}{ Eval. stage } & \multirow[b]{2}{*}{$\begin{array}{l}\text { Mean } \\
\text { (sd) } \\
\mathrm{N}\end{array}$} & \multicolumn{5}{|c|}{ Number of strings - All observations } & \multirow{2}{*}{$\begin{array}{c}\text { Kruskal-Wallis test } \\
p=0.802\end{array}$} \\
\hline & & $\begin{array}{c}\text { Overall } \\
16.35 \\
(7.83) \\
438\end{array}$ & $\begin{array}{c}\text { Baseline } \\
16.45 \\
(8.75) \\
116\end{array}$ & $\begin{array}{c}\text { FutureInfo } \\
16.44 \\
(7.34) \\
104\end{array}$ & $\begin{array}{c}\text { PastInfo } \\
16.03 \\
(7.29) \\
106\end{array}$ & $\begin{array}{c}\text { PastWinUn } \\
16.03 \\
(7.40) \\
112\end{array}$ & \\
\hline Round 1 & $\begin{array}{l}\text { Mean } \\
(\mathrm{sd}) \\
\mathrm{N}\end{array}$ & $\begin{array}{c}18.68 \\
(8.44) \\
334\end{array}$ & $\begin{array}{c}18.59 \\
(9.23) \\
116\end{array}$ & $\begin{array}{l}- \\
- \\
-\end{array}$ & $\begin{array}{c}18.92 \\
(7.53) \\
106\end{array}$ & $\begin{array}{c}18.33 \\
(7.52) \\
112\end{array}$ & $p=0.824$ \\
\hline Round 2 & $\begin{array}{l}\text { Mean } \\
(\mathrm{sd}) \\
\mathrm{N}\end{array}$ & $\begin{array}{c}18.97 \\
(8.22) \\
438\end{array}$ & $\begin{array}{c}19.16 \\
(9.30) \\
116\end{array}$ & $\begin{array}{c}18.45 \\
(7.62) \\
104\end{array}$ & $\begin{array}{c}18.82 \\
(7.45) \\
106\end{array}$ & $\begin{array}{c}16.77 \\
(8.12) \\
112\end{array}$ & $p=0.136$ \\
\hline Round 3 & $\begin{array}{l}\text { Mean } \\
\text { (sd) } \\
\mathrm{N}\end{array}$ & $\begin{array}{c}21.74 \\
(7.04) \\
86 \\
\end{array}$ & $\begin{array}{c}21.57 \\
(7.18) \\
44 \\
\end{array}$ & $\begin{array}{c}21.93 \\
(6.96) \\
42 \\
\end{array}$ & - & - & $p=0.583$ \\
\hline & & \multicolumn{5}{|c|}{ Number of strings - Raw-performance pairing } & Kruskal-Wallis test \\
\hline Eval. stage & $\begin{array}{l}\text { Mean } \\
(\mathrm{sd}) \\
\mathrm{N}\end{array}$ & $\begin{array}{c}\text { Overall } \\
20.12 \\
(5.79) \\
198\end{array}$ & $\begin{array}{c}\text { Baseline } \\
20.84 \\
(5.38) \\
50\end{array}$ & $\begin{array}{c}\text { FutureInfo } \\
20.35 \\
(4.80) \\
46\end{array}$ & $\begin{array}{c}\text { PastInfo } \\
19.92 \\
(6.25) \\
48\end{array}$ & $\begin{array}{c}\text { PastWinUn } \\
19.44 \\
(6.53) \\
54\end{array}$ & $p=0.521$ \\
\hline Round 1 & $\begin{array}{l}\text { Mean } \\
(\mathrm{sd}) \\
\mathrm{N}\end{array}$ & $\begin{array}{c}19.01 \\
(8.21) \\
152\end{array}$ & $\begin{array}{c}19.96 \\
(8.17) \\
50\end{array}$ & $\begin{array}{l}- \\
- \\
-\end{array}$ & $\begin{array}{c}19.64 \\
(7.67) \\
48\end{array}$ & $\begin{array}{c}17.56 \\
(8.65) \\
54\end{array}$ & $p=0.114$ \\
\hline Round 2 & $\begin{array}{l}\text { Mean } \\
(\mathrm{sd}) \\
\mathrm{N}\end{array}$ & $\begin{array}{c}18.98 \\
(7.82) \\
198\end{array}$ & $\begin{array}{c}20.30 \\
(8.22) \\
50\end{array}$ & $\begin{array}{c}18.63 \\
(7.31) \\
46\end{array}$ & $\begin{array}{c}19.54 \\
(6.92) \\
48\end{array}$ & $\begin{array}{c}17.57 \\
(8.54) \\
54\end{array}$ & $p=0.116$ \\
\hline Round 3 & $\begin{array}{l}\text { Mean } \\
(\mathrm{sd}) \\
\mathrm{N}\end{array}$ & $\begin{array}{c}22.38 \\
(6.31) \\
44\end{array}$ & $\begin{array}{c}21.63 \\
(5.33) \\
22\end{array}$ & $\begin{array}{c}23.14 \\
(7.21) \\
22\end{array}$ & - & - & $p=0.335$ \\
\hline & & \multicolumn{5}{|c|}{ Number of strings - Contest-performance pairing } & Kruskal-Wallis test \\
\hline Eval. stage & $\begin{array}{l}\text { Mean } \\
(\mathrm{sd}) \\
\mathrm{N}\end{array}$ & $\begin{array}{c}\text { Overall } \\
13.03 \\
(7.65) \\
240 \\
\end{array}$ & $\begin{array}{c}\text { Baseline } \\
13.12 \\
(9.36) \\
66\end{array}$ & $\begin{array}{c}\text { FutureInfo } \\
13.34 \\
(7.55) \\
58\end{array}$ & $\begin{array}{c}\text { PastInfo } \\
12.81 \\
(6.52) \\
58\end{array}$ & $\begin{array}{c}\text { PastWinUn } \\
12.84 \\
(6.75) \\
58 \\
\end{array}$ & $p=0.983$ \\
\hline Round 1 & $\begin{array}{l}\text { Mean } \\
(\mathrm{sd}) \\
\mathrm{N}\end{array}$ & $\begin{array}{c}18.27 \\
(8.08) \\
182\end{array}$ & $\begin{array}{c}17.56 \\
(9.88) \\
66\end{array}$ & $\begin{array}{l}- \\
- \\
-\end{array}$ & $\begin{array}{c}18.31 \\
(7.42) \\
58\end{array}$ & $\begin{array}{c}19.05 \\
(6.27) \\
58\end{array}$ & $p=0.530$ \\
\hline Round 2 & $\begin{array}{l}\text { Mean } \\
(\mathrm{sd}) \\
\mathrm{N}\end{array}$ & $\begin{array}{c}17.73 \\
(8.49) \\
240\end{array}$ & $\begin{array}{c}18.30 \\
(10.02) \\
66\end{array}$ & $\begin{array}{c}18.31 \\
(7.91) \\
58\end{array}$ & $\begin{array}{c}18.22 \\
(7.87) \\
58\end{array}$ & $\begin{array}{c}16.02 \\
(7.71) \\
58\end{array}$ & $p=0.548$ \\
\hline Round 3 & $\begin{array}{l}\text { Mean } \\
\text { (sd) } \\
\mathrm{N}\end{array}$ & $\begin{array}{c}21.07 \\
(7.73) \\
42\end{array}$ & $\begin{array}{c}21.50 \\
(8.88) \\
22\end{array}$ & $\begin{array}{c}20.60 \\
(6.59) \\
20\end{array}$ & - & - & $p=1.000$ \\
\hline
\end{tabular}


Our main variables of interest are the measures of performance in round 2 as a function of the outcome of round 1. Figure 4 summarises the performance (as the number of strings correctly reversed) and time spent on the tasks in round 2 and the change of performance and time spent from round 1 to round 2 , by treatment and by the winning outcome in round 1 . The patterns emerging are in line with the expected direction of the biases arising from the direct comparisons of performance, due to the endogeneity issue discussed in Section 4.

When looking at absolute performance and time spent (left panels), winners in round 1 seem to complete more strings and spend more time in round 2. This comparison is similar to estimating equation (2). This observed difference may reflect a selection bias: Winners in round 1 may just happen to be better at the task. ${ }^{25}$ On the contrary, when looking at the changes in performance and time spent between round 1 and round 2 (right panels), we do not observe any clear difference between winners and losers of the round 1 . This comparison is similar to estimating equation (3). The absence of difference in the change of performance may reflect a risk of regression towards the mean: Participants who happen to perform unusually well in round 1 are more likely to win; In round 2, these participants may be more likely to be back to a normal (lower) level of performance. Such a selection pattern could explain why no difference is observed when using first differences.

Our identification strategy is specifically designed to solve the endogeneity issue arising when looking at levels and variations of performance and effort. The probability matching procedure compares winners in round 1 to their losing counterfactual who had very similar probabilities of winning in round $1 .{ }^{26}$

\footnotetext{
performance in other treatments where there were only one round in the evaluation stage.

${ }^{25}$ While such a concern should be alleviated with our pairing of contestants by abilities, residual differences can exist.

${ }^{26}$ This identification strategy can only be used to look at the effect of a success in round 1 on round 2 performance. It cannot, by design, be used in round 3 . The matching on round 2 winning probabilities would not control for differences in performance in round 1. See Appendix D for a more detailed discussion.
} 
Figure 4: A summary of performance (measured by the number of tasks completed) \& effort (measured by time spent on the tasks) in round 2 (left panels) and variation of performance and effort between round 2 and round 1 (right panels). The right panels do not include the FutureInfo treatment, since participants do not need to make efforts in the first round there.

Round 2: strings completed

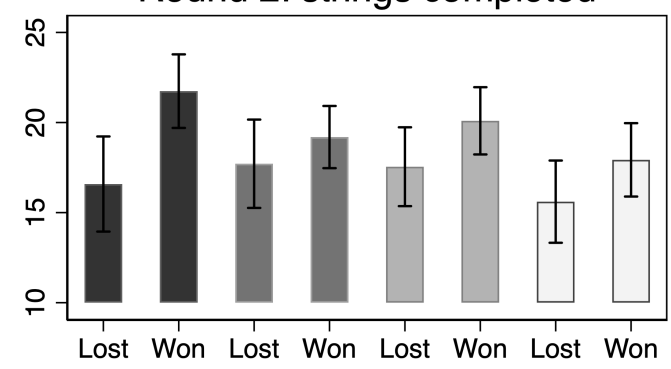

Round 2: time spent

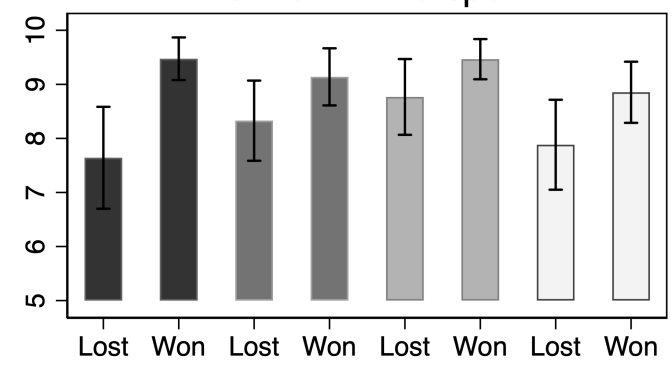

Round 2: change in strings completed
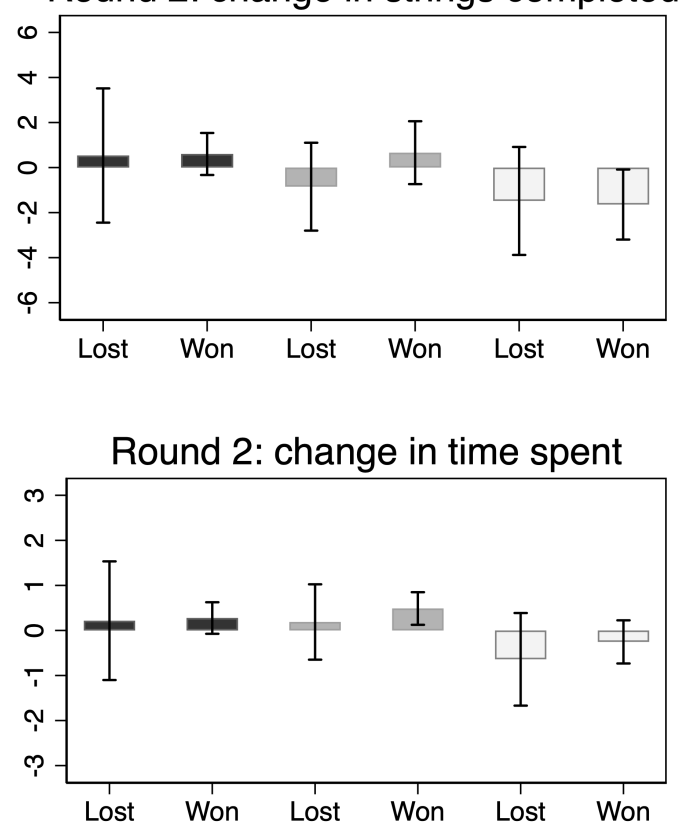

\subsection{Identifying the momentum effects}

Table 3 shows the average treatment effect of winning on different "effort" measures and on participants' winning probabilities. All results refer to the estimation of equation (6) (in the Appendix) where the causal effect of winning is calculated as the difference between a player's change of effort from round 1 to round $2, \Delta e_{i}$, to his counterfactual, $\Delta \widehat{e}_{i} .{ }^{27}$ Table 3 presents the result for the two different pairing conditions separately in the top two panels. The results are very similar in both conditions. The last part of Table 3 presents the estimation on the aggregated data. ${ }^{28}$ Aggregating the two conditions allows us to gain greater statistical power, and hence we focus on the aggregated results in the following discussion.

\footnotetext{
${ }^{27}$ For the FutureInfo treatment, we use the difference with the evaluation stage: the first of the initial round that was used to pair players. As round 1 success is purely random, there is no risk of regression towards the mean in this specific treatment.

${ }^{28}$ In the aggregated estimations, observations are matched with observations from the same pairing condition.
} 
Table 3: Effect of winning round 1 on "effort" measures and winning probability in round 2, estimated by LLR matching. For estimates with all observations, the matching is done within each pairing condition. The bandwidth for the LLR is set to 0.025 with an Epanechnikov kernel weighting function. Standard errors are indicated in brackets and constructed by standard bootstrap (2000 replications). $\mathrm{N}$ is the total number of observations in each treatment and $\mathrm{N}$ (supp.) is the total number of observations on the common support. Significance at ${ }^{*} 10 \%$, ${ }^{* *} 5 \%$, $* * * 1 \%$.

\begin{tabular}{|c|c|c|c|c|c|c|}
\hline \multicolumn{7}{|c|}{ All observations } \\
\hline Treatment & $\begin{array}{l}\text { Strings } \\
\text { completed }\end{array}$ & $\begin{array}{l}\text { Time } \\
\text { spent }\end{array}$ & Productivity & $\begin{array}{l}\text { Winning } \\
\text { prob. }\end{array}$ & $\mathrm{N}$ & $\mathrm{N}$ (supp.) \\
\hline Baseline & $\begin{array}{l}4.01^{* *} \\
(1.74)\end{array}$ & $\begin{array}{l}1.86^{* * *} \\
(0.70)\end{array}$ & $\begin{array}{l}0.38^{* * *} \\
(0.15)\end{array}$ & $\begin{array}{l}0.20^{* * *} \\
(0.05)\end{array}$ & 116 & 90 \\
\hline FutureInfo & $\begin{array}{l}0.90 \\
(1.22)\end{array}$ & $\begin{array}{l}0.54 \\
(0.50)\end{array}$ & $\begin{array}{l}0.01 \\
(0.07)\end{array}$ & $\begin{array}{l}0.05 \\
(0.03)\end{array}$ & 104 & 104 \\
\hline PastInfo & $\begin{array}{l}2.67^{* *} \\
(1.11)\end{array}$ & $\begin{array}{l}0.63 \\
(0.42)\end{array}$ & $\begin{array}{l}0.17^{* *} \\
(0.08)\end{array}$ & $\begin{array}{l}0.08^{* * *} \\
(0.03)\end{array}$ & 106 & 100 \\
\hline PastWinUninformative & $\begin{array}{l}0.33 \\
(1.62)\end{array}$ & $\begin{array}{l}0.56 \\
(0.66)\end{array}$ & $\begin{array}{l}-0.01 \\
(0.10)\end{array}$ & $\begin{array}{l}0.04 \\
(0.04)\end{array}$ & 112 & 94 \\
\hline \multicolumn{7}{|c|}{ Raw-performance pairing } \\
\hline Treatment & $\begin{array}{l}\text { Strings } \\
\text { completed }\end{array}$ & $\begin{array}{l}\text { Time } \\
\text { spent }\end{array}$ & Productivity & $\begin{array}{l}\text { Winning } \\
\text { prob. }\end{array}$ & $\mathrm{N}$ & N(supp.) \\
\hline Baseline & $\begin{array}{l}4.46^{*} \\
(2.45)\end{array}$ & $\begin{array}{l}1.96^{*} \\
(1.04)\end{array}$ & $\begin{array}{l}0.65^{* *} \\
(0.29)\end{array}$ & $\begin{array}{l}0.26^{* * *} \\
(0.09)\end{array}$ & 50 & 32 \\
\hline FutureInfo & $\begin{array}{l}0.30 \\
(1.76)\end{array}$ & $\begin{array}{l}0.28 \\
(0.70)\end{array}$ & $\begin{array}{l}-0.03 \\
(0.11)\end{array}$ & $\begin{array}{l}0.02 \\
(0.04)\end{array}$ & 46 & 46 \\
\hline PastInfo & $\begin{array}{l}2.93 \\
(1.80)\end{array}$ & $\begin{array}{l}0.52 \\
(0.70)\end{array}$ & $\begin{array}{l}0.26^{*} \\
(0.15)\end{array}$ & $\begin{array}{l}0.08^{*} \\
(0.04)\end{array}$ & 48 & 46 \\
\hline PastWinUninformative & $\begin{array}{l}1.46 \\
(2.64)\end{array}$ & $\begin{array}{l}1.15 \\
(0.99)\end{array}$ & $\begin{array}{l}-0.06 \\
(0.14)\end{array}$ & $\begin{array}{l}0.09 \\
(0.06)\end{array}$ & 54 & 38 \\
\hline \multicolumn{7}{|c|}{ Contest-performance pairing } \\
\hline Treatment & $\begin{array}{l}\text { Strings } \\
\text { completed }\end{array}$ & $\begin{array}{l}\text { Time } \\
\text { spent }\end{array}$ & Productivity & $\begin{array}{l}\text { Winning } \\
\text { prob. }\end{array}$ & $\mathrm{N}$ & $\mathrm{N}($ supp.) \\
\hline Baseline & $\begin{array}{l}3.76 \\
(2.39)\end{array}$ & $\begin{array}{l}1.81^{*} \\
(0.93)\end{array}$ & $\begin{array}{l}0.23 \\
(0.16)\end{array}$ & $\begin{array}{l}0.16^{* *} \\
(0.07)\end{array}$ & 66 & 58 \\
\hline FutureInfo & $\begin{array}{l}1.38 \\
(1.58)\end{array}$ & $\begin{array}{l}0.75 \\
(0.69)\end{array}$ & $\begin{array}{l}0.04 \\
(0.10)\end{array}$ & $\begin{array}{l}0.06 \\
(0.04)\end{array}$ & 58 & 58 \\
\hline PastInfo & $\begin{array}{l}2.46^{*} \\
(1.45)\end{array}$ & $\begin{array}{l}0.72 \\
(0.54)\end{array}$ & $\begin{array}{l}0.10 \\
(0.08)\end{array}$ & $\begin{array}{l}0.09^{* * *} \\
(0.03)\end{array}$ & 58 & 54 \\
\hline PastWinUninformative & $\begin{array}{l}-0.44 \\
(2.07)\end{array}$ & $\begin{array}{l}0.17 \\
(0.87)\end{array}$ & $\begin{array}{l}0.03 \\
(0.15)\end{array}$ & $\begin{array}{l}0.01 \\
(0.06)\end{array}$ & 58 & 56 \\
\hline
\end{tabular}


In Baseline, we observe a significant positive momentum on all performance measures. At the extensive margin, we find that winners spent on average more time in round 2 than losers (difference of $1.86 \mathrm{~min}, p=0.01$ ). At the intensive margin, winners display a higher productivity. On average they complete 0.38 more strings per minute $(p=0.01)$. These two joint effects combine into a significantly larger performance for winners who complete 4.01 strings more in round $2(p=0.02)$. It means that participants, with similar probability of winning in round 1, diverge in their performance in the second round based on their success in the first round. With this increase in performance, the round 1 winner increases his/her chance of winning in round 2 by 20 percentage points $(p<0.001)$.

Result 1 (Positive momentum) We observe a positive causal effect of winning on performance in the Baseline treatment.

The origin of this effect is a priori unclear. It can reflect a strategic momentum due to asymmetric incentives to expend effort after winning (versus losing), or a psychological momentum, or both. Taken on its own, the result from the Baseline treatment does not allow us to disentangle the two possible effects. In order to identify the source of the effect, we now turn to the FutureInfo and PastInfo treatments.

In FutureInfo, we do not observe a significant difference in round 2 between the first round winners and losers. Randomly assigned round 1 winners do not spend significantly more time in the second round (diff $=0.54, p=0.28$ ), they do not become more productive (diff $=0.01, p=0.89$ ) and they do not complete more strings in round 2 (diff $=0.90, p=0.46$ ). This absence of effect is found in both pairing conditions.

Result 2 (No effect of future information) We do not observe an effect of winning when we remove the past information (even if the standard strategic momentum is still predicted to be present).

In PastInfo, we find that winning has a significant impact on productivity and the number of strings completed. Winners spent on average 0.63 minutes more on the task, though the difference is not statistically significant $(p=0.14)$ at the conventional level. The productivity of winners is higher by 0.17 tasks per minute ( $p=0.03$ ). Overall, the performance of round 1 winners is greater by an average of 2.67 strings in round 2 $(p=0.02)$. This greater performance is associated with an increase of winning chances of 8 percentage points $(p<0.001)$. As winners are randomly determined in round 3 in PastInfo, the information about the future of the contest is turned off. The presence of a positive effect in PastInfo points to the existence of an effect of past information in the contest. 
Result 3 (Positive effect of past information) We observe a positive causal effect of winning on performance in the PastInfo treatment.

The joint results of these three experimental treatments provide two clear conclusions. First, winning has indeed a positive causal effect on players' performance. Second, the evidence point towards an effect of having experienced a success in the past. $^{29}$

Looking at the role of information updating with the PastWinUninformative treatment, we observe that there is no significant effect of winning when success per se does not provide additional information to the player. In the aggregated results, winners did not spend significantly more time than losers in round $2(p=0.39)$, they did not complete more strings per minute $(p=0.94)$ and, as a consequence, they did not significantly increase their number of strings completed relative to losers $(p=0.84)$. We can therefore not reject the null hypothesis that there is no momentum effect in PastWinUninformative, in line with the prediction from Hypothesis 4. This result suggests that the momentum observed in PastInfo is driven by the informational content of a win.

Result 4 No momentum when success is not informative We do not find evidence of a causal effect of winning on performance when winning does not give participants any additional information about their relative strength in the contest.

\section{Investigating the mechanisms}

We find an absence of the momentum caused by the standard strategic effect from future information and an existence of positive momentum caused by the informational content of past win associated with the experience of a successful performance. In this section, we further investigate and discuss the possible mechanisms underlying these results.

\footnotetext{
${ }^{29}$ The coefficients are slightly different in magnitude in the Baseline and the PastInfo treatments. These differences are not statistically significant ( $p=0.52,0.14$, and 0.23 for strings completed, time spent, and productivity respectively). Note that, as discussed in Section 3.1, the Baseline and the PastInfo treatments have different game structures. The momentum could potentially have different magnitudes in these two treatments. For instance, a psychological momentum could be smaller in PastInfo than in Baseline because participants only anticipate one more round of contest in PastInfo, versus two in Baseline. Therefore, we are primarily interested in the existence or not of an effect in each treatment (not on them being equal).
} 


\subsection{Sophistication}

A possible explanation for the absence of a strategic effect of winning could be the participants' cognitive limitations: they may fail to appreciate the strategic aspects of the whole contest. By backward induction, the strategic effect should arise if participants take into account the cost of future effort in round 3. It is this cost which creates an asymmetry in incentives in round 2 between winners and losers.

Figure 5: An example of the game with two steps of backward induction. Participants were invited to play as the blue player and to indicate which initial choice they would make, starting from the centre to ensure that the outcome of the game is a blue node. After the initial choice, players successively take turn playing left $(l)$ or right $(r)$. Only one possible choice in the first move ensures a win. In this example, only the choice of 1 ensures a win $(W)$ for the blue player.

(a) Graphical representation in the game

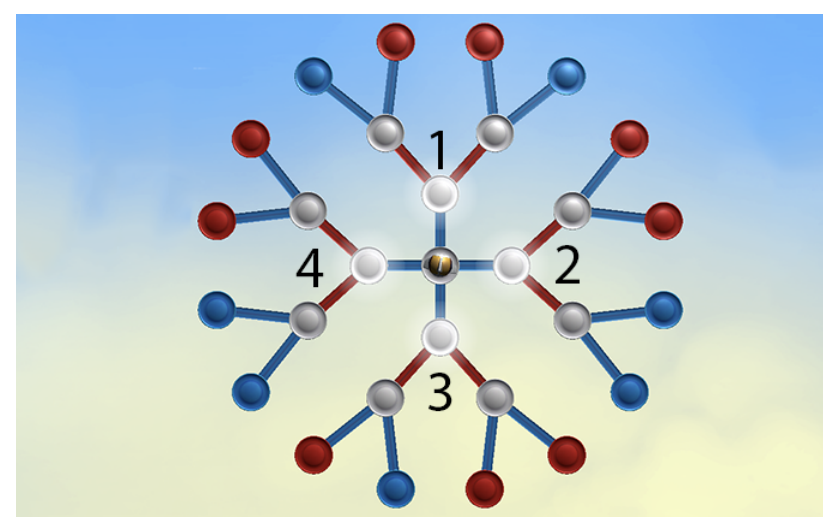

(b) Extensive-form representation of the game

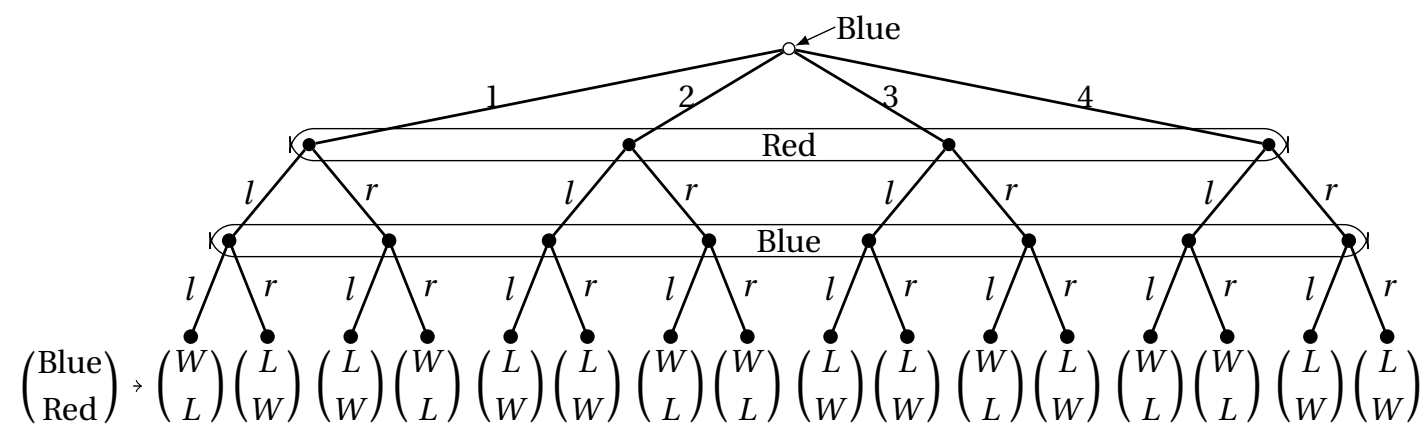

Failures to fully reason by backward induction have previously been observed (Binmore et al., 2002; Johnson et al., 2002). We therefore investigate whether it could be the reason that participants fail to display a strategic effect of success. ${ }^{30}$ For this purpose, we include four games assessing the degree to which participants are able to do backward induction in the post-experiment questionnaire when we ran sessions for the contest-performance paring condition. These games are taken from Grabiszewski and

\footnotetext{
${ }^{30}$ We thank an anonymous reviewer for this suggestion.
} 
Horenstein (2019). They are graphical representations of extensive-form games where two players play alternatively. The two players are represented by the colours blue and red, respectively. The end nodes of the game are associated either with a blue or a red colour which indicates the final winner. The blue player is the first mover and his/her goal is to secure the possibility to land on a blue node at the end of the game. Figure 5 shows one of the game in its graphical representation (used in the experiment) and its corresponding extensive form. ${ }^{31}$

Each game starts with four possible moves for the blue player and then the red and blue players play alternately following the node picked by the blue player in the first move, with two possible moves each time afterwards. The player is asked what he/she would do as the first (blue) mover to win the game. Before playing, participants were shown explanations about the game with one simple example. We selected four games where the blue player has to choose between four possible actions as a first move. Only one of them can, by backward induction, ensure a win for the blue player. The games had different degrees of difficulty with participants having to do backward induction over 1, 2, 3, and 4 steps respectively. Participants were paid one Australian dollar for each correct answer. The results of the participants reflect this increasing difficulty with the proportions of right answer being $95 \%, 57 \%, 60 \%$, and $11 \%$ in the order of difficulty of the games. On average, participants answered correctly to 2.2 games.

Table 4: Effect of winning round 1 on "effort" measures and winning probability in round 2, estimated by LLR matching. Observations in the FutureInfo treatment under the contest-performance pairing condition are split into two subsamples by the number of backward-induction games participants did correctly. The bandwidth for the LLR is set to 0.025 with an Epanechnikov kernel weighting function. Standard errors constructed by standard bootstrap (2000 replications) and are indicated in brackets.

\begin{tabular}{lllll}
\hline \hline \multicolumn{5}{l}{ FutureInfo treatment } \\
& $\begin{array}{l}\text { Strings } \\
\text { completed }\end{array}$ & $\begin{array}{l}\text { Time } \\
\text { spent }\end{array}$ & Productivity & $\begin{array}{l}\text { Winning } \\
\text { prob. }\end{array}$ \\
\cline { 2 - 5 } Numb. games right $\leq 2$ & 1.31 & 0.79 & 0.07 & 0.06 \\
$(\mathrm{~N}=36)$ & $(2.18)$ & $(0.90)$ & $(0.14)$ & $(0.06)$ \\
Numb. games right $>2$ & 0.27 & 0.26 & -0.09 & 0.03 \\
$(\mathrm{~N}=22)$ & $(2.35)$ & $(0.76)$ & $(0.20)$ & $(0.07)$ \\
\hline
\end{tabular}

In order to assess whether strategic sophistication and in particular the ability to do backward induction influences the presence of strategic momentum effect in $\mathrm{Fu}$ tureInfo treatment, we estimated the causal effect of winning round 1 on two sub-

\footnotetext{
${ }^{31}$ All the games are depicted in Figure 10 in Appendix F.
} 
samples: the sample of participants having solved two games or less and the sample of participants having solved more than two games. Table 4 shows the results. We find no evidence that participants who solved more of the backward induction games display a greater effect of success. It suggests that participants did not differ in their strategic behaviour based on their ability to do backward induction.

\subsection{Beliefs and confidence}

In spite of our pairing of players by ability, there may be residual differences. Even if there are no significant differences, the information about a past success could still have an impact if players believe that residual differences in ability exist and update their beliefs accordingly. While our design aims to create a setting as close as possible from common-knowledge of equal ability, we cannot rule out the possibility that players think they differ somewhat from each other. For instance, a player may believe that he could have done better in the initial round and therefore is likely paired with a weaker player.

A conjecture that motivated our Hypothesis 4 is that the effect of winning may be driven by participants updating favourably their belief in their relative strength after a success, which further influences their performance or incentive to make effort. To assess this prediction, we asked participants how likely they thought they would win the next round before each round started (except for the neutral rounds). Given that winning is partly random with the stochastic contest function, we also asked participants how likely they thought their performance would be higher than their opponent in the next round (but this question was only presented in the contest-performance pairing sessions). If the informational content of a win influences confidence, players' beliefs in their chance of winning and in their performance being better should be higher in Baseline and PastInfo treatments than in the PastWinUninformative treatment. Using our matching approach we can estimate the causal effect of winning on players' confidence in round 2 . Table 5 shows the results of these estimations. ${ }^{32}$

In all treatments, winning leads participants to become significantly more confident when considering chances of winning. The observed effect is the largest in Baseline (20.52). This effect is slightly smaller in PastInfo (16.24), but becomes significantly smaller in the PastWinUninformative treatment (10.08, $p=0.02) .{ }^{33}$ Interestingly, the effect in PastWinUninformative has the similar level as in FutureInfo (11.73, $p=0.69$ ) where winning is random in the first round and players do not learn anything about

\footnotetext{
${ }^{32}$ See Table 9 and 10 in the online Appendix for detailed summary statistics of the beliefs elicited in all rounds.

${ }^{33}$ Similarly, we focus on the pooled data while discussing beliefs on winning chances.
} 
Table 5: Effect of winning round 1 on elicited confidence in round 2's winning chances and relative performance, estimated by LLR matching. For estimates with all observations, the matching is done within each condition. The bandwidth for the LLR is set to 0.025 with an Epanechnikov kernel weighting function. Standard errors are constructed by standard bootstrap (2000 replications) and indicated in brackets. Significance at ${ }^{*} 10 \%,{ }^{* *} 5 \%,{ }^{* *} 1 \%$.

\begin{tabular}{|c|c|c|c|}
\hline \multicolumn{4}{|c|}{ All observations } \\
\hline Treatment & Win. chances & Performance & $\mathrm{N}$ \\
\hline Baseline & $\begin{array}{l}20.52^{* * *} \\
(3.15)\end{array}$ & & 116 \\
\hline FutureInfo & $\begin{array}{l}11.73^{* * *} \\
(2.85)\end{array}$ & & 104 \\
\hline PastInfo & $\begin{array}{l}16.24^{* * *} \\
(3.66)\end{array}$ & & 106 \\
\hline PastWinUninformative & $\begin{array}{l}10.08^{* *} \\
(4.40)\end{array}$ & & 112 \\
\hline \multicolumn{4}{|c|}{ Raw-performance pairing } \\
\hline Treatment & Win. chances & Performance & $\mathrm{N}$ \\
\hline Baseline & $\begin{array}{l}18.58^{* * *} \\
(4.56)\end{array}$ & & 50 \\
\hline FutureInfo & $\begin{array}{l}9.96^{* *} \\
(3.96)\end{array}$ & & 46 \\
\hline PastInfo & $\begin{array}{l}14.76^{* * *} \\
(5.70)\end{array}$ & & 48 \\
\hline PastWinUninformative & $\begin{array}{l}7.23 \\
(4.99)\end{array}$ & & 54 \\
\hline
\end{tabular}

Contest-performance pairing

\begin{tabular}{llll}
\hline Treatment & Win. chances & Performance & $\mathrm{N}$ \\
\cline { 2 - 4 } Baseline & $21.58^{* * *}$ & $19.47^{* * *}$ & 66 \\
FutureInfo & $(4.14)$ & $(4.41)$ & \\
& $13.14^{* * *}$ & $8.28^{*}$ & 58 \\
PastInfo & $(4.04)$ & $(4.51)$ & \\
& $17.51^{* * *}$ & $13.48^{* * *}$ & 58 \\
PastWinUninformative & $(4.69)$ & $(4.25)$ & \\
& $12.01^{*}$ & -0.24 & 58 \\
\hline
\end{tabular}


their relative strength from winning. The fact that the effect of beliefs is significant in PastWinUninformative and FutureInfo suggests that the mere fact of winning a random contest in round 1 does impacts participants' beliefs about their chances of winning in round 2.

When we ask participants about their belief of being the better performer in round 2 (rather than about their chances of winning), we observe that the effect of winning becomes close to zero (-0.24) and not significant in PastWinUninformative ( $p=0.97$ ), even though it stays high for participants in the Baseline (19.47, $p<0.01$ ) and PastInfo (13.48, $p=0.01$ ). This question has the advantage of excluding any possible effect of winning on the participants' perception about the randomness of the contest (e.g. "feeling lucky" after winning the first round). ${ }^{34}$

To investigate the possible effect of confidence on performance, we first regress the change in effort between the two rounds on the change in confidence, controlling for the winning probability. The results are presented in Table 6 . We observe that changes in confidence are positively correlated with an increase in effort in the Baseline treatment $(p=0.04$ ). The effect just fails to be significant at the conventional $5 \%$ level in the PastInfo treatment ( $p=0.056$ ). This indicates that, for a given probability of winning in round 1, participants who experienced a larger increase in confidence also had a larger increase in performance.

These regressions results are supportive of a possible role of the change in confidence in the change of performance. Our setting allows us to look further into this possibility. The win outcome in the round 1 is random conditionally on the winning probability. We can therefore use an initial win as an instrument for confidence to look at the effect of an increase in confidence, induced by an initial success, on performance. The lower part of Table 6 also presents these results. We observe that confidence has a positive effect on performance. The effect is the strongest and significant only in the Baseline ( $p=0.01$ ) and PastInfo treatment ( $p=0.04$ ) where an initial success is potentially informative about the relative strength of the players.

These results do not definitely prove that confidence has a causal effect. A win could have other indirect effects via different variables. Nonetheless, they are in line with the idea that a higher self-confidence may drive a higher performance after a success. In psychology, lack of confidence is often considered to be associated with "selfdoubts" which "hinders adept execution of acquired capabilities" (Bandura, 1982). On

\footnotetext{
${ }^{34}$ Winners in FutureInfo are still marginally more likely to believe that they will perform better in round 2 after winning round 1 even though the outcome in this round was determined randomly by the computer $(8.28, p=0.07)$. These results might suggest, after an initial win, participants are not just feeling lucky about their future winning chances but also more confident about their future performance, even though winning was purely random and should not give them any feedback about their relative strength.
} 
Table 6: Regressions of the effect of the change in confidence on the change of effort from round 1 (R1) to round 2 (R2), controlling for each contestant's winning probability in R1. In the IV regressions, the change in confidence is instrumented by whether or not the contestant had won R1. Note that in FutureInfo the winning probability in $\mathrm{R} 1$ is $50 \%$ for every contestants as $\mathrm{R} 1$ winning outcome was determined randomly, and hence is omitted. For the same reason, the effort in the second round of the evaluation stage is used as the R1 effort in FutureInfo. Significance at ${ }^{*} 10 \%,{ }^{* *} 5 \%,{ }^{* *} 1 \%$.

\begin{tabular}{|c|c|c|c|c|}
\hline Effort-change (R1 to R2) & Baseline & FutureInfo & PastInfo & PastWinUn \\
\hline \multicolumn{5}{|l|}{ OLS regression } \\
\hline Confidence-change (R1 to R2) & $\begin{array}{l}0.09^{* *} \\
(0.04)\end{array}$ & $\begin{array}{l}0.02 \\
(0.04)\end{array}$ & $\begin{array}{l}0.06^{*} \\
(0.03)\end{array}$ & $\begin{array}{l}0.04 \\
(0.04)\end{array}$ \\
\hline Winning probability in R1 & $\begin{array}{l}-17.96^{* * *} \\
(3.14)\end{array}$ & & $\begin{array}{l}-14.03^{* * *} \\
(3.99)\end{array}$ & $\begin{array}{l}-5.14 \\
(5.43)\end{array}$ \\
\hline Constant & $\begin{array}{l}9.81^{* * *} \\
(1.73)\end{array}$ & $\begin{array}{l}<0.01 \\
(0.64) \\
\end{array}$ & $\begin{array}{l}6.99 \\
(2.07) \\
\end{array}$ & $\begin{array}{l}1.10 \\
(2.82) \\
\end{array}$ \\
\hline \multicolumn{5}{|l|}{ IV regression } \\
\hline Confidence-change (R1 to R2) & $\begin{array}{l}0.20^{* * *} \\
(0.08)\end{array}$ & $\begin{array}{l}0.08 \\
(0.11)\end{array}$ & $\begin{array}{l}0.15^{* *} \\
(0.07)\end{array}$ & $\begin{array}{l}0.03 \\
(0.15)\end{array}$ \\
\hline Winning probability in R1 & $\begin{array}{l}-18.75^{* * *} \\
(3.23)\end{array}$ & - & $\begin{array}{l}-13.87^{* * *} \\
(4.09)\end{array}$ & $\begin{array}{l}-4.90 \\
(6.39)\end{array}$ \\
\hline Constant & $\begin{array}{l}10.55^{* * *} \\
(1.81)\end{array}$ & $\begin{array}{l}-0.15 \\
(0.69)\end{array}$ & $\begin{array}{l}7.01^{* * *} \\
(2.12)\end{array}$ & $\begin{array}{l}0.95 \\
(3.49)\end{array}$ \\
\hline
\end{tabular}

the other hand, the confidence gained from success can lead to an "altered and felt state of mind in which a performer senses things going unstoppably his or her way." This enables him/her "to perform at a level not ordinarily possible" (Iso-Ahola and Dotson, 2014). In economics, Compte and Postlewaite (2004) have discussed the implications of such a psychological effect to understand performance.

One possibility is that the mechanisms underlying such an effect are purely psychological/physiological in a way which do not lay themselves to an analysis in terms of rational strategy. Another possibility could be, however, that this "psychological momentum" is the result of a rational strategy in contests, conceived as games of incomplete information, where players do not know their relative strength initially. As the game progresses, they get information about their relative strength. In particular, after an initial win, players learned they are more likely to be the strongest of the two players. This information could intuitively lead winners to expend more effort as future success is perceived more likely.

This possible mechanism calls for the investigation of dynamic contests as games of incomplete information. Until now, only a few specific cases of dynamic contests have been solved in a setting with incomplete information (Konrad, 2009; Münster, 
2009; Ederer, 2010; Kubitz, 2015; Miklós-Thal and Ullrich, 2016). The unknown heterogeneity of players adds a layer of complexity to the game: it not only has to be solved by backward induction starting from the end, but the equilibrium strategy at the end of the contest depends on the Bayesian beliefs formed from the equilibrium strategies and outcomes in all the previous rounds. Given that earlier outcomes influence later beliefs and later strategies, some non-trivial strategies can emerge in such settings, such as sand-bagging whereby contestants who believe they are strong expend less effort to bias the beliefs of the other player (Münster, 2009; Kubitz, 2015).

We should note that, however, some aspects of our results raise some doubts about the momentum we observe being the result of a fully rational strategy. First, we found that there is no strategic momentum, even though we would expect it to exist if players follow rational strategies. Second, we find that most participants failed at doing the hardest backward induction game in the post-experiment questionnaire (only $11 \%$ found the solution). This game only features simple binary comparisons of outcomes at four nodes of a simple game tree. It is allegedly easier to solve than a best-of-three contest which requires to identify the equilibrium strategy at each round to identify its (expected) payoffs. Third, we find that players update positively their beliefs about their chances of winning in the FutureInfo treatment even though winning (randomly) in round 1 has no significant effect on their chances of winning in round 2. It raises doubts on the ability of participants to form accurate Bayesian beliefs. Nonetheless, rational strategies in dynamic contests with incomplete information may be worth investigating to improve our understanding of actual behaviour in contests.

\section{Conclusion}

We find a clear positive causal effect of winning in a dynamic contest. This effect is not generated by the standard game-theoretic explanation, which identifies that an initial outcome creates an asymmetry in incentives between the leader and the laggard. Our results point instead to the effect of winning on the players' confidence. We observe that winning increases players' relative performances when it increases their beliefs in their relative strength. On the contrary, when players are fully informed about their performance-and, therefore, winning does not bring them any additional information-we do not observe a positive effect of an early success.

The main result of our study is that, whether for fully behavioural or for strategic reasons, players' belief updating seems to be the driving factor behind the momentum effect we observe, unlike what is predicted by most game-theoretic models of dynamic contests. 
Understanding how competitors form and update their beliefs about their relative strength is critical to understand their motivation and strategies. Whether these beliefs are accurate or not, they may be influenced by past success and the updated beliefs may influence future performance. Even with an initially even playing field, subjective self-confidence can play a critical role in future performance and therefore contribute to putting identical people on different paths in terms of long term success.

\section{References}

Abadie, Alberto, and Guido W Imbens. 2008. "On the failure of the bootstrap for matching estimators." Econometrica, 76(6): 1537-1557.

Apesteguia, Jose, and Ignacio Palacios-Huerta. 2010. "Psychological pressure in competitive environments: Evidence from a randomized natural experiment." American Economic Review, 100(5): 2548-64.

Araujo, Felipe A., Erin Carbone, Lynn Conell-Price, Marli W. Dunietz, Ania Jaroszewicz, Rachel Landsman, Diego Lamé, Lise Vesterlund, Stephanie W. Wang, and Alistair J. Wilson. 2016. "The slider task: an example of restricted inference on incentive effects." Journal of the Economic Science Association, 2(1): 1-12.

Bandura, Albert. 1982. "Self-efficacy mechanism in human agency." American psychologist, 37(2): 122.

Bergerhoff, Jan, and Agnes Vosen. 2015. "Can being behind get you ahead? Reference Dependence and Asymmetric Equilibria in an Unfair Tournament.” Bonn Econ Discussion Papers.

Berger, Jonah, and Devin Pope. 2011. "Can Losing Lead to Winning?" Management Science, 57(5): 817-827.

Binmore, Ken, John McCarthy, Giovanni Ponti, Larry Samuelson, and Avner Shaked. 2002. "A backward induction experiment." Journal of Economic theory, 104(1): 4888.

Chen, Daniel L, Martin Schonger, and Chris Wickens. 2016. "oTree-An open-source platform for laboratory, online, and field experiments." Journal of Behavioral and Experimental Finance, 9: 88-97.

Cohen-Zada, Danny, Alex Krumer, and Ze'ev Shtudiner. 2017. "Psychological momentum and gender." Journal of Economic Behavior Organization, 135: 66 - 81. 
Compte, Olivier, and Andrew Postlewaite. 2004. "Confidence-enhanced performance." The American Economic Review, 94(5): 1536-1557.

Dechenaux, Emmanuel, Dan Kovenock, and Roman. Sheremeta. 2015. "A survey of experimental research on contests, all-pay auctions and tournaments." Experimental Economics, 18(4): 609-669.

Ederer, Florian. 2010. "Feedback and motivation in dynamic tournaments." Journal of Economics \& Management Strategy, 19(3): 733-769.

Erkal, Nisvan, Lata Gangadharan, and Boon Han Koh. 2018. "Monetary and nonmonetary incentives in real-effort tournaments." European Economic Review, 101: 528-545.

Fan, Jianqing. 1992. "Design-adaptive nonparametric regression." Journal of the American statistical Association, 87(420): 998-1004.

Ferrall, Christopher, and Anthony A Smith Jr. 1999. "A sequential game model of sports championship series: theory and estimation." The Review of Economics and Statistics, 81(4): 704-719.

Fu, Qiang, Changxia Ke, and Fangfang Tan. 2015. " "Success breeds success" or "Pride goes before a fall"?: Teams and individuals in multi-contest tournaments." Games and Economic Behavior, 94: 57 - 79.

Fu, Qiang, Jingfeng Lu, and Yue Pan. 2015. “Team contests with multiple pairwise battles." The American Economic Review, 105(7): 2120-2140.

Gächter, Simon, Lingbo Huang, and Martin Sefton. 2016. "Combining "real effort" with induced effort costs: the ball-catching task." Experimental economics, 19(4): 687-712.

Gauriot, Romain, and Lionel Page. 2019. "Does success breed success? A quasiexperiment on strategic momentum in dynamic contests." Economic Journal, 129(624): 3107-3136.

Gill, David, and Victoria Prowse. 2012. "A structural analysis of disappointment aversion in a real effort competition." American Economic Review, 102(1): 469-503.

Gill, David, and Victoria Prowse. 2014. "Gender differences and dynamics in competition: The role of luck." Quantitative Economics, 5(2): 351-376. 
Grabiszewski, Konrad, and Alex R Horenstein. 2019. "Skills, Complexity, and Backward Induction." Available at SSRN 3337169.

Greiner, Ben. 2015. "Subject pool recruitment procedures: organizing experiments with ORSEE." Journal of the Economic Science Association, 1(1): 114-125.

Härdle, Wolfgang Karl, Marlene Müller, Stefan Sperlich, and Axel Werwatz. 2012. Nonparametric and semiparametric models. Springer Science \& Business Media.

Harris, Christopher, and John Vickers. 1987. "Racing with uncertainty." The Review of Economic Studies, 54(1): 1-21.

Heckman, James J., Hidehiko Ichimura, and Petra Todd. 1998. "Matching As An Econometric Evaluation Estimator.” The Review of Economic Studies, 65(2): 261-294.

Hollard, Guillaume, Sébastien Massoni, and Jean-Christophe Vergnaud. 2016. "In search of good probability assessors: an experimental comparison of elicitation rules for confidence judgments.” Theory and Decision, 80(3): 363-387.

Huck, Steffen, Nora Szech, and Lukas M Wenner. 2015. "More effort with less pay: On information avoidance, belief design and performance." CESifo Working Paper Series No. 5542.

Iso-Ahola, Seppo E, and Charles $O$ Dotson. 2014. "Psychological momentum: Why success breeds success." Review of General Psychology, 18(1): 19-33.

Iso-Ahola, Seppo E, and KEN Mobily. 1980. "" Psychological momentum": A phenomenon and an empirical (unobtrusive) validation of its influence in a competitive sport tournament." Psychological Reports, 46(2): 391-401.

Johnson, Eric J, Colin Camerer, Sankar Sen, and Talia Rymon. 2002. “Detecting failures of backward induction: Monitoring information search in sequential bargaining." Journal of Economic Theory, 104(1): 16-47.

Klumpp, Tilman, and Mattias K Polborn. 2006. "Primaries and the New Hampshire effect.” Journal of Public Economics, 90(6): 1073-1114.

Kocher, Martin G, Marc V Lenz, and Matthias Sutter. 2012. "Psychological pressure in competitive environments: New evidence from randomized natural experiments.” Management Science, 58(8): 1585-1591.

Konrad, Kai A. 2009. Strategy and dynamics in contests. Oxford University Press. 
Konrad, Kai A, and Dan Kovenock. 2006. "Equilibrium and Efficiency in the Tug-ofWar." SFB/TR 15 Discussion Paper.

Konrad, Kai A., and Dan Kovenock. 2009. "Multi-battle contests." Games and Economic Behavior, 66(1): 256 - 274.

Kubitz, Greg. 2015. “Repeated contests with private information.” New York: New York University.

Mago, Shakun D, and Laura Razzolini. 2019. "Best-of-five contest: An experiment on gender differences." Journal of Economic Behavior \& Organization, 162: 164-187.

Mago, Shakun D., and Roman M. Sheremeta. 2019. "New Hampshire Effect: behavior in sequential and simultaneous multi-battle contests." Experimental Economics, 22: $325-349$.

Mago, Shakun D., Roman M. Sheremeta, and Andrew Yates. 2013. "Best-of-three contest experiments: Strategic versus psychological momentum." International Journal of Industrial Organization, 31(3): 287 - 296.

Malueg, David A, and Andrew J Yates. 2010. "Testing contest theory: evidence from best-of-three tennis matches.” The Review of Economics and Statistics, 92(3): 689692.

Markman, Keith D, and Corey L Guenther. 2007. "Psychological momentum: Intuitive physics and naive beliefs." Personality and Social Psychology Bulletin, 33: 800812.

Merton, Robert K. 1968. “The Matthew Effect in Science.” Science, 159(3810): 56-63.

Miklós-Thal, Jeanine, and Hannes Ullrich. 2016. "Career prospects and effort incentives: Evidence from professional soccer." Management Science, 62(6): 1645-1667.

Miller, Joshua Benjamin, and Adam Sanjurjo. 2018. "Surprised by the gambler's and hot hand fallacies? A truth in the law of small numbers." Econometrica, 86(6): 20192047.

Münster, Johannes. 2009. "Repeated contests with asymmetric information.” Journal of Public Economic Theory, 11(1): 89-118.

Nickell, Stephen. 1981. "Biases in dynamic models with fixed effects." Econometrica: Journal of the Econometric Society, 1417-1426. 
Paserman, M Daniele. 2010. "Gender Differences in Performance in Competitive Environments? Evidence from Professional Tennis Players.” Working paper.

Robertson, Ian H. 2012. The winner effect: The neuroscience of success and failure. Macmillan.

Rubin, Donald B. 1974. "Estimating causal effects of treatments in randomized and nonrandomized studies." Journal of educational Psychology, 66(5): 688.

Smith, Jeffrey A., and Petra E. Todd. 2005. "Does matching overcome LaLonde's critique of nonexperimental estimators?" Journal of Econometrics, 125(1): 305 - 353.

Todd, Petra E. 2010. "Matching Estimators." Microeconometrics, , ed. Steven N. Durlauf and Lawrence E. Blume, 108-121. London:Palgrave Macmillan UK.

Tong, Kwok-kit, and Kwok Leung. 2002. “Tournament as a motivational strategy: Extension to dynamic situations with uncertain duration." Journal of Economic Psychology, 23(3): 399-420.

Tullock, Gordon. 1980. "Efficient rent seeking.” In Towards a theory of the rent-seeking society. , ed. JM Buchanan, Tollison RD and Tullock G, 97-112. Texas AM University Press.

Van de Rijt, Arnout, Soong Moon Kang, Michael Restivo, and Akshay Patil. 2014. "Field experiments of success-breeds-success dynamics." Proceedings of the $\mathrm{Na}$ tional Academy of Sciences, 111(19): 6934-6939. 
For Online Publication Only

\section{A Summary statistics}

A.1 Detailed summary statistics for all four treatments 


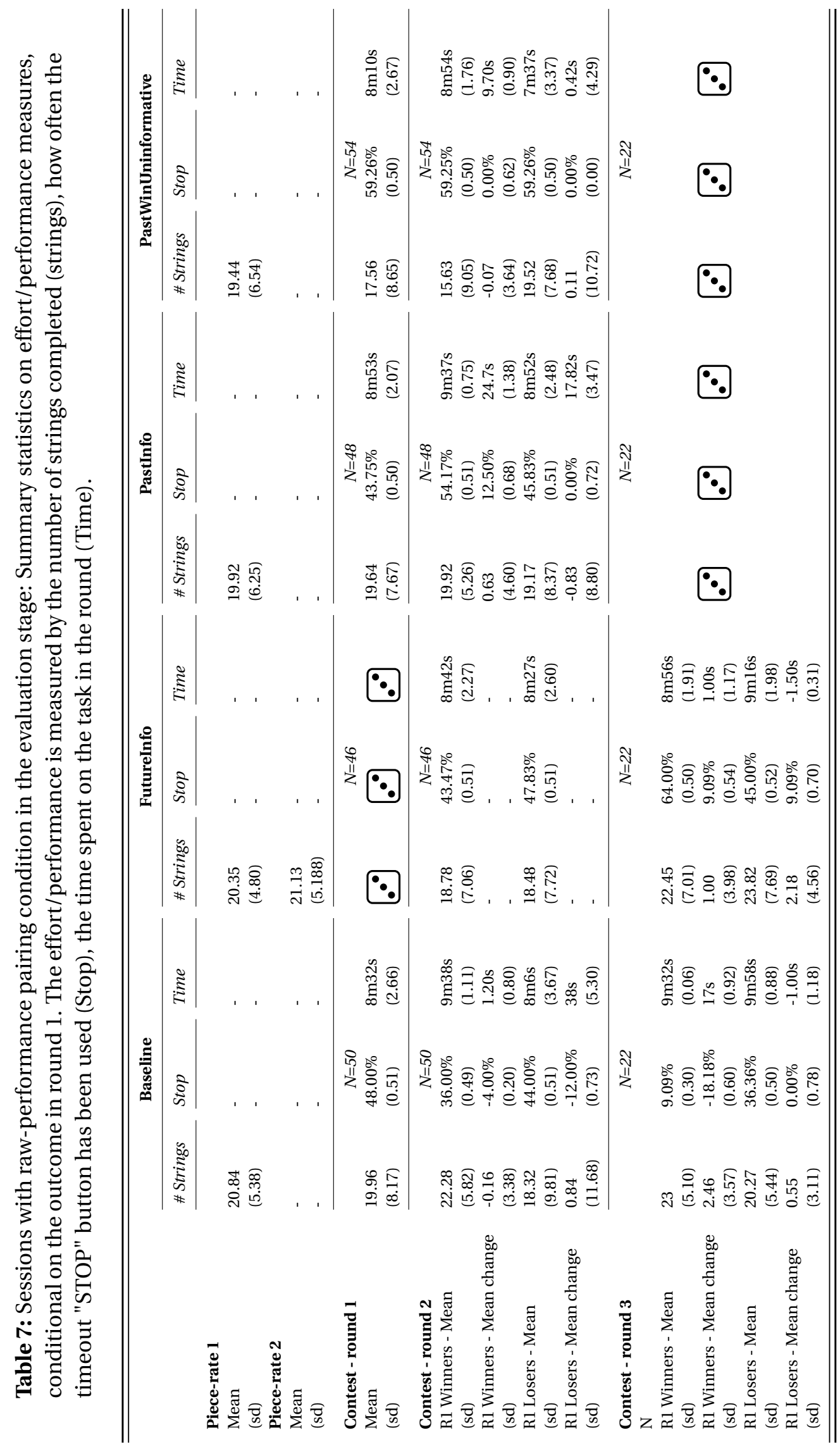




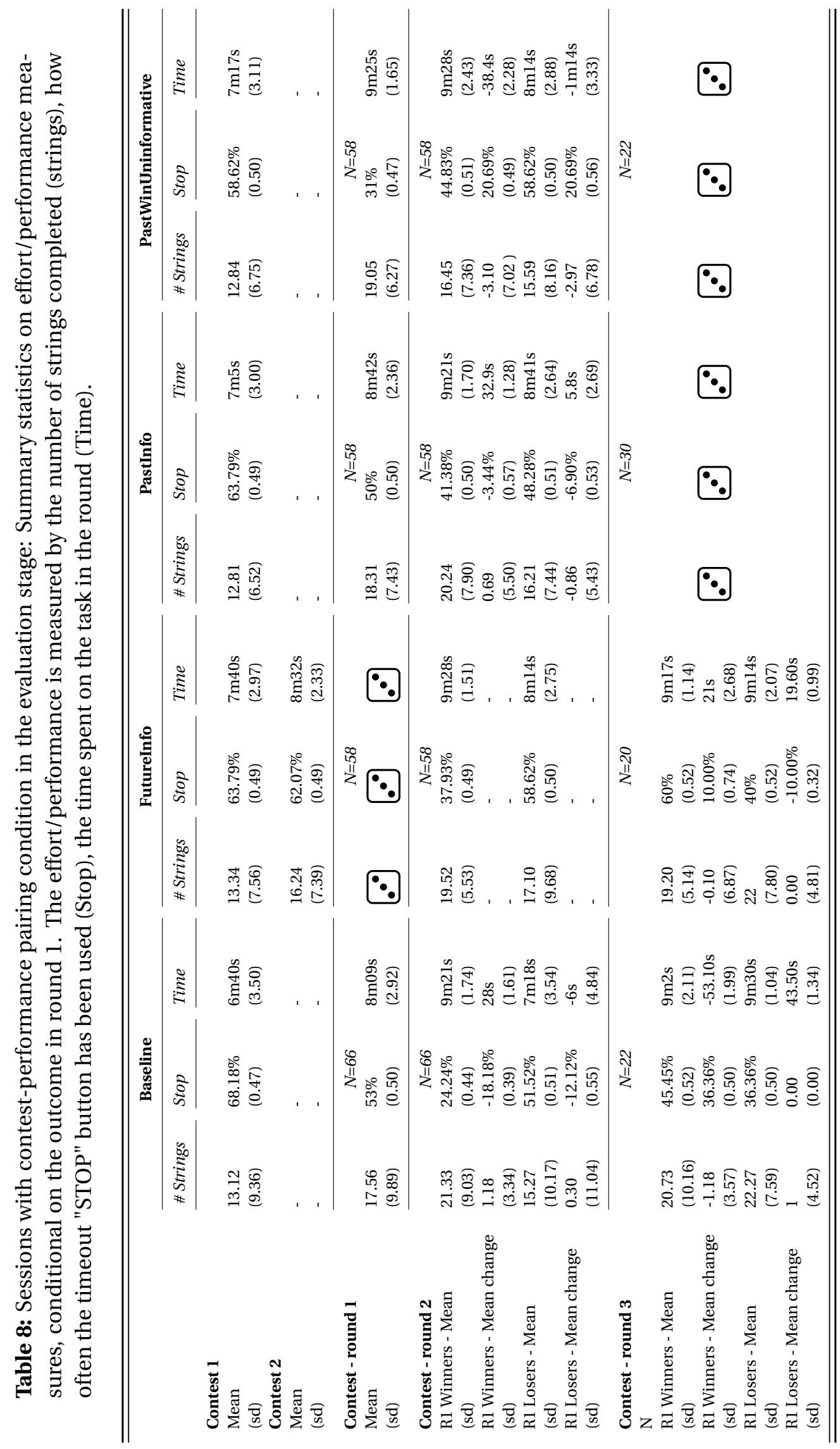




\section{A.2 Summary statistics on players' beliefs about their chances to win each round}

Table 9 presents summary statistics on the participants beliefs to win a round elicited at the beginning of each round. In round 1 we observe that this belief is close to $50 \%$ in each treatment which indicate that, following our pairing procedure, participants do not expect to be better than their opponent on average. The participants who end up winning round 1 had similar beliefs about their chance of winning at the beginning of round 1 . However, after the outcome of round 1, participants update their beliefs with round 1 winners updating theirs upwards and round 1 losers updating theirs downwards. ${ }^{35}$. In both Baseline. The beliefs of round 1 winners (round 2 losers) and round 1 losers (round 1 winners) all go back to around $50 \%$ in round 3 . The difference in confidence is another potential heterogeneity between players, besides raw skill. The matching procedure allows us to control for these differences by estimating the effect of winning which comes from the purely random part of the contest on belief updating.

Table 9: Summary statistics on players beliefs about their chances to win the round (in \%), conditional on the outcome in round 1 and pooling both the rawperformance and contest-performance pairing.

\begin{tabular}{|c|c|c|c|c|}
\hline & Baseline & FutureInfo & PastInfo & PastWinUn \\
\hline \multicolumn{5}{|l|}{ Contest - round 1} \\
\hline Mean & 54.78 & - & 54.99 & 54.31 \\
\hline (sd) & (18.44) & - & (17.95) & (19.62) \\
\hline R1 Winners - Mean & 55.47 & - & 54.09 & 52.82 \\
\hline (sd) & (18.38) & - & $(14.46)$ & $(20.14)$ \\
\hline R1 Losers - Mean & 54.09 & - & 55.89 & 55.8 \\
\hline$(\mathrm{sd})$ & (18.62) & - & (20.97) & (19.16) \\
\hline Difference - $p$-value & 0.69 & & 0.61 & 0.42 \\
\hline \multicolumn{5}{|l|}{ Contest - round 2} \\
\hline R1 Winners - Mean & 61.09 & 58.40 & 60.47 & 55.80 \\
\hline$(\mathrm{sd})$ & (18.53) & (14.20) & $(17.45)$ & $(17.54)$ \\
\hline R1 Winners - Mean change & 5.62 & 8.40 & 6.38 & 2.98 \\
\hline$(\mathrm{sd})$ & $(9.79)$ & $(14.20)$ & $(9.88)$ & $(17.00)$ \\
\hline R1 Losers - Mean & 42.53 & 46.67 & 47.25 & 47.95 \\
\hline$(\mathrm{sd})$ & $(21.85)$ & $(14.73)$ & $(26.68)$ & $(24.23)$ \\
\hline R1 Losers - Mean change & -11.55 & -3.33 & -8.64 & -7.86 \\
\hline (sd) & $(17.34)$ & $(14.73)$ & $(20.85)$ & (20.92) \\
\hline \multicolumn{5}{|l|}{ Contest - round 3} \\
\hline R1 Winners, R2 Losers - Mean & 54.00 & 54.81 & & \\
\hline$(\mathrm{sd})$ & $(21.91)$ & $(15.97)$ & & \\
\hline R1 Winners, R2 Losers - Mean change & -9.23 & -2.71 & & \\
\hline$(\mathrm{sd})$ & (12.39) & $(17.96)$ & & \\
\hline R1 Losers, R2 Winners - Mean & 52.77 & 55.04 & & \\
\hline$(\mathrm{sd})$ & $(23.52)$ & (19.97) & & \\
\hline R1 Losers, R2 Winners - Mean change & 9.91 & 7.95 & & \\
\hline$(\mathrm{sd})$ & $(13.42)$ & $(16.07)$ & & \\
\hline
\end{tabular}

\footnotetext{
${ }^{35}$ Note the mean change is calculated based on the difference between beliefs in round 2 minus $50 \%$ for the FutureInfo treatment.
} 
Table 10: Summary statistics on players beliefs about their relative performance in each round (in \%) under the contest-performance paring condition, conditional on the outcome in round 1.

\begin{tabular}{|c|c|c|c|c|}
\hline & Baseline & FutureInfo & PastInfo & PastWinUn \\
\hline \multicolumn{5}{|l|}{ Contest - round 1} \\
\hline Mean & 59.67 & - & 58.02 & 58.60 \\
\hline (sd) & (19.89) & - & $(19.54)$ & $(20.91)$ \\
\hline R1 Winners - Mean & 62.67 & - & 59.24 & 56.31 \\
\hline (sd) & $(17.29)$ & - & $(15.63)$ & $(23.66)$ \\
\hline R1 Losers - Mean & 56.67 & - & 56.79 & 60.90 \\
\hline (sd) & $(22.05)$ & - & $(23.03)$ & $(17.87)$ \\
\hline Difference - $p$-value & 0.22 & & 0.64 & 0.41 \\
\hline \multicolumn{5}{|l|}{ Contest - round 2} \\
\hline R1 Winners - Mean & 66.58 & 54.59 & 66.62 & 57.14 \\
\hline$(\mathrm{sd})$ & (16.88) & $(15.67)$ & $(16.90)$ & $(16.32)$ \\
\hline R1 Winners - Mean change & 3.91 & 4.59 & 7.38 & 0.83 \\
\hline$(\mathrm{sd})$ & $(10.40)$ & $(15.67)$ & $(8.34)$ & $(24.68)$ \\
\hline R1 Losers - Mean & 44.45 & 46.31 & 50.79 & 58.69 \\
\hline$(\mathrm{sd})$ & $(23.78)$ & $(19.00)$ & $(24.73)$ & $(28.42)$ \\
\hline R1 Losers - Mean change & -12.21 & -3.69 & -6.00 & -2.21 \\
\hline (sd) & $(23.72)$ & $(19.00)$ & $(17.89)$ & $(27.89)$ \\
\hline \multicolumn{5}{|l|}{ Contest - round 3} \\
\hline R1 Winners, R2 Losers - Mean & 56.82 & 47.50 & & \\
\hline$(\mathrm{sd})$ & $(22.28)$ & $(15.32)$ & & \\
\hline R1 Winners, R2 Losers - Mean change & -12.73 & -1.00 & & \\
\hline$(\mathrm{sd})$ & $(12.52)$ & $(14.68)$ & & \\
\hline R1 Losers, R2 Winners - Mean & 45.27 & 57.00 & & \\
\hline$(\mathrm{sd})$ & $(29.65)$ & $(27.10)$ & & \\
\hline R1 Losers, R2 Winners - Mean change & 2.55 & 8.50 & & \\
\hline$(\mathrm{sd})$ & $(10.11)$ & $(17.01)$ & & \\
\hline
\end{tabular}

\section{B Matching}

In order to recover the causal effect of winning, we want to estimate the (counterfactual) potential change in performance a player would experience after a win or a loss. Using the Rubin (1974) framework, let's denote $\Delta e_{i}^{1}$ and $\Delta e_{i}^{0}$ the potential outcomes in terms of change of effort for player $i$ if, respectively, the player wins in round 1 $\left(w i n_{i 1}=1\right)$ or not $\left(w i n_{i 1}=0\right)$. Given that we know the exact winning probability determined by the performance of the player, conditional on this probability the win/loss outcome is purely random (i.e. unrelated/exogenous to the player's characteristics). ${ }^{36}$ As a consequence, the conditional independence assumption holds:

$$
\left(\Delta e_{i}^{1}, \Delta e_{i}^{0}\right) \Perp w i n_{i 1} \mid p_{i 1}
$$

Conditioning on winning probability (using the matching approach) we can there-

\footnotetext{
${ }^{36}$ Due to the endogeneity problem, players who ended up winning are on average stronger players (than those who lost). For that reason, looking at the performance in the second round of the first round winners is likely different from looking at the potential performance any player would have in the second round after winning the first round. This problem disappears when conditioning on the first round winning probability.
} 
fore identify the causal effect of winning. To do so we match winners and losers who have similar ex-ante winning probabilities. We implement a local linear regression matching which compares each winner to a weighted average of losers with similar probabilities (Heckman, Ichimura and Todd, 1998). More weight is given to counterfactual observations with closer matching probability. ${ }^{37}$

Let's consider a game where $n$ participants compete in pairs in a given round. Let $\mathcal{M}_{i}$ denote the matching neighbourhood of observation $i$, which includes all observations $j$ that had a different outcome $w_{i n}$ (win/loss) in the first round and were located within a bandwidth $h$ in regard to their winning probability:

$$
\mathcal{M}_{i}=\left\{j \in\{1, . ., n\}:\left\|p_{i}-p_{j}\right\|<h \cap w_{i n} n_{j 1} \neq w_{i n} n_{i 1}\right\}
$$

We estimate the following regression in a given matching neighbourhood of observation $i$ :

$$
\min _{a_{i}, b_{i}} \sum_{j \in \mathcal{M}_{i}}\left(\Delta e_{j}-a_{i}-b_{i} \times\left(p_{i}-p_{j}\right)\right)^{2} K\left(\frac{p_{j}-p_{i}}{h}\right)
$$

Where $a_{i}$ and $b_{i}$ are the parameters of the local linear regression and $K$ is a kernel weighting function with a bandwidth $h$ (see Fan, 1992). The prediction of the above regression is a synthetic counterfactual to observation $i\left(\Delta \widehat{e_{i}}\right)$. Figure 6 shows how this counterfactual is estimated.

Let $\widehat{\Delta e_{i}^{1}}$ and $\widehat{\Delta e_{i}^{0}}$ be these estimated counterfactual after a win and a loss, respectively. We can compute the individual effect $\left(\widehat{\beta}_{i}\right)$ of winning as:

$$
\widehat{\beta}_{i}= \begin{cases}\Delta e_{i}-\widehat{\Delta e_{i}^{0}} & \text { if } w_{i n} n_{i 1}=1 \\ \widehat{\Delta e_{i}^{1}}-\Delta e_{i} & \text { if } w i n_{i 1}=0\end{cases}
$$

And the average treatment effects $(\widehat{\beta})$, henceforth denoted as ATE, is:

$$
\widehat{\beta}=\frac{1}{n} \sum_{i=1}^{N} \widehat{\beta}_{i}
$$

\footnotetext{
${ }^{37}$ As shown by Fan (1992), local linear regression performs strictly better than local weighted averaging like kernel regression.
} 
Figure 6: Representation of the construction of the counterfactual value of a variable of interest $(Y)$ for winners. counterfactual values of losing players are calculated similarly using winning players.

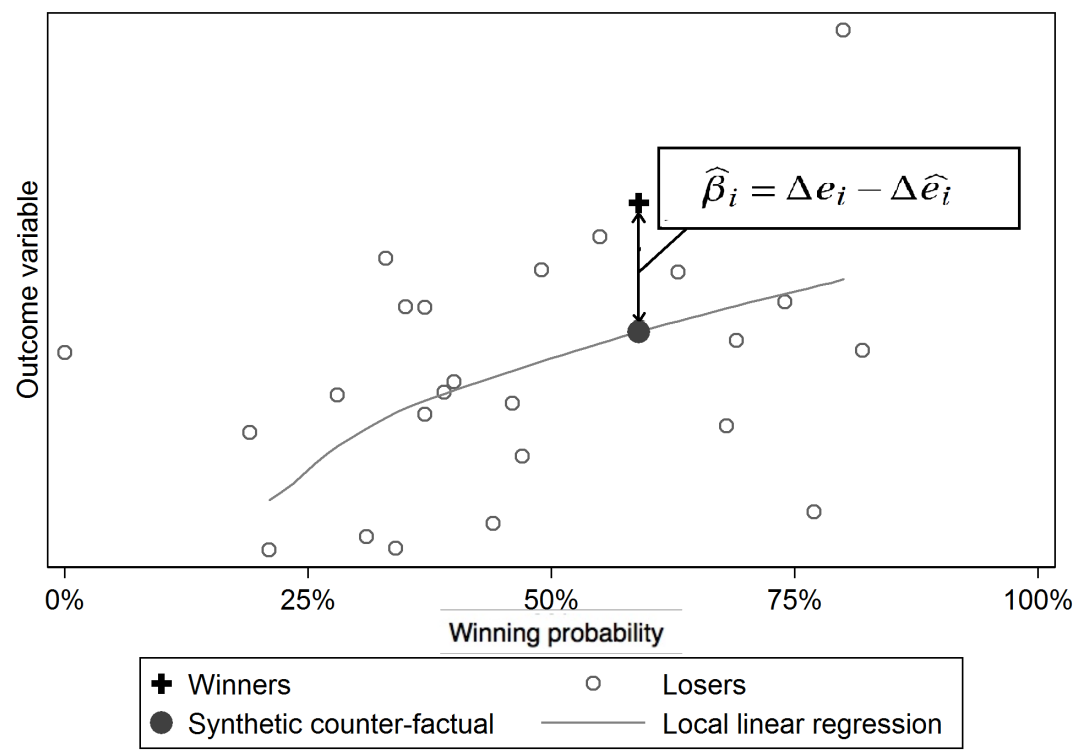

\section{Robustness checks}

\section{C.1 Balance tests across treatments}

Table 11: Comparisons of demographics between treatments. We asked subjects "Did you enjoy the task?", "Do you think effort pays off in this game?" and "On a 0 -10 scale, do you see yourself as a person that usually takes risk ( 0 being never, 10 being always)?". Answers to these questions are summarised in "\% Enjoyed task", "\% Effort pays off", and "Mean risk" respectively. P-values are from Kruskal-Wallis tests.

\begin{tabular}{|c|c|c|c|c|c|c|}
\hline & Overall & Baseline & FutureInfo & PastInfo & PastWinUn & P-values \\
\hline $\begin{array}{l}\text { \% Male } \\
(\mathrm{sd})\end{array}$ & $\begin{array}{l}56 \% \\
(0.50)\end{array}$ & $\begin{array}{l}60 \% \\
(0.49)\end{array}$ & $\begin{array}{l}58 \% \\
(0.49)\end{array}$ & $\begin{array}{l}48 \% \\
(0.50)\end{array}$ & $\begin{array}{l}56 \% \\
(0.50)\end{array}$ & $p=0.279$ \\
\hline $\begin{array}{l}\text { Mean age } \\
(\mathrm{sd})\end{array}$ & $\begin{array}{l}22.82 \\
(5.56)\end{array}$ & $\begin{array}{l}23.55 \\
(6.36)\end{array}$ & $\begin{array}{l}22.88 \\
(6.24)\end{array}$ & $\begin{array}{l}22.44 \\
(4.70)\end{array}$ & $\begin{array}{l}22.37 \\
(4.67)\end{array}$ & $p=0.721$ \\
\hline $\begin{array}{l}\text { \% Enjoyed task } \\
\text { (sd) }\end{array}$ & $\begin{array}{l}75 \% \\
(0.43)\end{array}$ & $\begin{array}{l}78 \% \\
(0.42)\end{array}$ & $\begin{array}{l}73 \% \\
(0.44)\end{array}$ & $\begin{array}{l}73 \% \\
(0.45)\end{array}$ & $\begin{array}{l}76 \% \\
(0.43)\end{array}$ & $p=0.808$ \\
\hline $\begin{array}{l}\text { \% Effort pays off } \\
\text { (sd) }\end{array}$ & $\begin{array}{l}68 \% \\
(0.47)\end{array}$ & $\begin{array}{l}66 \% \\
(0.48)\end{array}$ & $\begin{array}{l}70 \% \\
(0.46)\end{array}$ & $\begin{array}{l}65 \% \\
(0.48)\end{array}$ & $\begin{array}{l}71 \% \\
(0.45)\end{array}$ & $p=0.666$ \\
\hline $\begin{array}{l}\text { Mean risk } \\
\text { (sd) }\end{array}$ & $\begin{array}{l}6.12 \\
(2.10)\end{array}$ & $\begin{array}{l}6.61 \\
(2.20)\end{array}$ & $\begin{array}{l}6.22 \\
(1.80)\end{array}$ & $\begin{array}{l}5.99 \\
(2.11)\end{array}$ & $\begin{array}{l}6.25 \\
(2.26)\end{array}$ & $p=0.625$ \\
\hline
\end{tabular}




\section{C.2 Common support}

It is standard to check the size of the common support (set of observations where the matching scores overlap) when using a propensity score matching. In our case, our matching strategy is facilitated by the fact that the Tullock function produces winning probabilities concentrated around 50\%. Therefore most winners in our sample can be matched with losers with a similar winning probability and vice-versa.

The empirical distribution of the round 1 winning probabilities is represented in Figure 7. FutureInfo is not represented since all the observations can be matched: the winning probability is $50 \%$ for all participants in round 1, by design. In Baseline, the common support includes participants having a chance to win the first round between $41 \%$ and $59 \%(N=32)$ under raw-performance pairing and between $8 \%$ to $92 \%$ ( $\mathrm{N}=58)$ under contest-perforamnce paring. In PastInfo and PastWinUninformative, the common support includes pairs whose propensity score range between $27 \%$ and $73 \%(N=46)$ and between $36 \%$ to $70 \%(\mathrm{~N}=38)$ respectively under raw-performance pairing. These numbers become $28 \%$ to $72 \%(\mathrm{~N}=54)$ and $30 \%$ to $70 \%(\mathrm{~N}=56)$ respectively under contest-performance pairing. Detailed summary statistics over the common support are presented in Tables 12 and 13.

Figure 7: Distribution of winning probability in each treatment conditions. Top panels: Raw-performance pairing; Bottom panels: Contest-performance pairing.
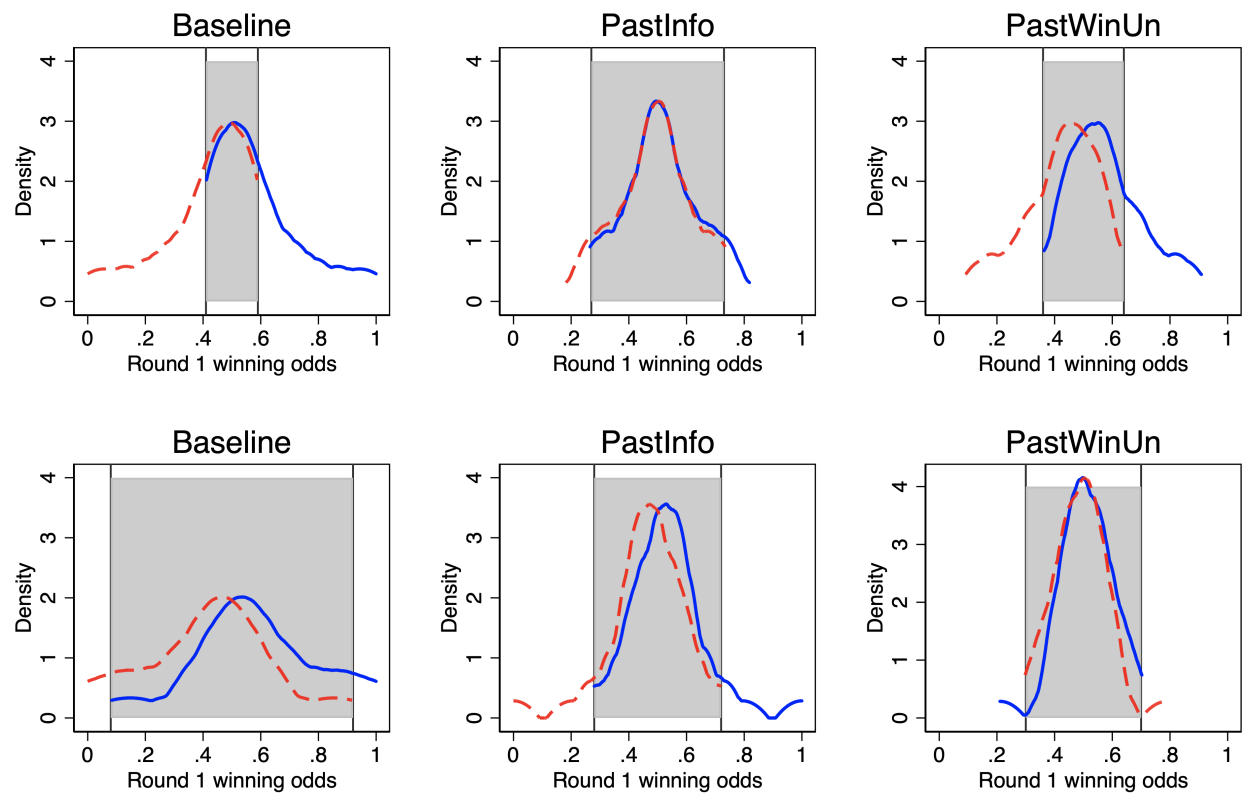

\begin{tabular}{|ll}
\hline Winners $\quad-----$ Losers & Common Support \\
\hline
\end{tabular}


Table 12: Summary statistics over the common support (Raw-performance pairing). P-values are for Mann-Whitney tests between winners and losers.

\begin{tabular}{|c|c|c|c|c|c|c|c|}
\hline & & \multicolumn{2}{|c|}{$\begin{array}{l}\text { Change in \# } \\
\text { strings }\end{array}$} & \multicolumn{2}{|c|}{$\begin{array}{l}\text { Change in } \\
\text { time spent }\end{array}$} & \multicolumn{2}{|c|}{$\begin{array}{l}\text { Change in } \\
\text { productivity }\end{array}$} \\
\hline & & Winners & Losers & Winners & Losers & Winners & Losers \\
\hline \multirow[t]{3}{*}{ Baseline } & Mean & -0.25 & -4.63 & -0.066 & -2 & 0 & -0.58 \\
\hline & se & $(0.955)$ & (2.427) & $(0.232)$ & (1.035) & $(0.075)$ & $(0.261)$ \\
\hline & MW test & \multicolumn{2}{|c|}{$p=0.279$} & \multicolumn{2}{|c|}{$p=0.480$} & \multicolumn{2}{|c|}{$p=0.151$} \\
\hline \multirow[t]{3}{*}{ PastInfo } & Mean & 0.86 & -1.65 & 0.43 & 0.02 & -0.02 & -0.24 \\
\hline & se & $(0.946)$ & (1.669) & $(0.292)$ & $(0.681)$ & $(0.133)$ & $(0.060)$ \\
\hline & MW test & \multicolumn{2}{|c|}{$p=0.473$} & \multicolumn{2}{|c|}{$p=0.432$} & \multicolumn{2}{|c|}{$p=0.176$} \\
\hline \multirow[t]{3}{*}{ PastWinUninformative } & Mean & -0.74 & -2.95 & 0.18 & -1.36 & -1.12 & -0.06 \\
\hline & se & $(3.813)$ & (10.450) & $(1.071)$ & $(4.086)$ & $(0.251)$ & $(0.459)$ \\
\hline & MW test & \multicolumn{2}{|c|}{$p=0.671$} & \multicolumn{2}{|c|}{$p=0.744$} & \multicolumn{2}{|c|}{$p=0.827$} \\
\hline
\end{tabular}

Table 13: Summary statistics over the common support (Contest-performance pairing). P-values are for Mann-Whitney tests between winners and losers.

\begin{tabular}{|c|c|c|c|c|c|c|c|}
\hline & & \multicolumn{2}{|c|}{$\begin{array}{l}\text { Change in \# } \\
\text { strings }\end{array}$} & \multicolumn{2}{|c|}{$\begin{array}{l}\text { Change in } \\
\text { time spent }\end{array}$} & \multicolumn{2}{|c|}{$\begin{array}{l}\text { Change in } \\
\text { productivity }\end{array}$} \\
\hline & & Winners & Losers & Winners & Losers & Winners & Losers \\
\hline \multirow[t]{3}{*}{ Baseline } & Mean & 1.52 & -1.45 & 0.55 & -0.90 & 0.01 & -0.13 \\
\hline & $\mathrm{Se}$ & (3.313) & (10.294) & (1.708) & (4.473) & $(0.235)$ & (0.776) \\
\hline & MW test & \multicolumn{2}{|c|}{$\mathrm{p}=0.096$} & \multicolumn{2}{|c|}{$\mathrm{p}=0.129$} & \multicolumn{2}{|c|}{$\mathrm{p}=0.22$} \\
\hline \multirow[t]{3}{*}{ PastInfo } & Mean & 0.85 & -1.37 & 0.58 & -0.13 & -0.052 & -0.14 \\
\hline & $\mathrm{Se}$ & (5.634) & (5.009) & (1.322) & (2.481) & $(0.358)$ & $(0.235)$ \\
\hline & MW test & $\mathrm{p}=\mathrm{c}$ & 270 & $\mathrm{p}=0$ & & $\mathrm{p}=0$. & 10 \\
\hline \multirow[t]{3}{*}{ PastWinUninformative } & Mean & -3.18 & -2.89 & -0.66 & -1.19 & -0.17 & -0.16 \\
\hline & Se & (7.139) & (6.893) & (2.320) & (3.378) & $(0.570)$ & $(0.379)$ \\
\hline & MW test & \multicolumn{2}{|c|}{$\mathrm{p}=1.00$} & \multicolumn{2}{|c|}{$\mathrm{p}=0.710$} & \multicolumn{2}{|c|}{$\mathrm{p}=0.967$} \\
\hline
\end{tabular}

\section{C.3 Bandwidth selection}

We relax the assumption of a bandwidth of $2.5 \%$ for the local linear regression to check the robustness of our results. First, we use a leave-one-out cross-validation method (Härdle et al., 2012) to determine the bandwidth minimising the Asymptotic Mean 
Integrated Squared Errors (AMISE). This bandwidth is referred as the "optimal bandwidth" in typical applications. It is however not necessarily optimal in a matching estimation. The identification strategy requires observations to be matched with very close observations in order to ensure that they are similar. The best bandwidth in a matching approach may therefore be smaller than the one minimising the AMISE. We therefore only use this different bandwidth as a robustness check, which might be different from our initial choice of a small bandwidth.

The leave-one-out cross-validation method consists in estimating the AMISE of the estimator by running the model on the whole sample minus one observation and compare the model prediction for this observation with the actual value of the variable studied. By successively leaving out each observation in the sample once, one can estimate an error for each observation. The average of these errors provides an estimate of the AMISE of the model given its bandwidth. The "optimal bandwidth" is the one that minimises the mean square error of the predictions. The optimal bandwidth identified through this procedure are displayed in Table 14 using data from rawperformance pairing and in Table 15 using data from contest-performance pairing. As shown, our main results (illustrated in Table 3 in the main text) still hold for these optimal bandwidths.

We further assess the sensitivity of our results to bandwidth selection by looking at how our results vary with different bandwidths. We start by estimating the model with a bandwidth of 0.01 , and progressively increase it up to the point where all observations on the common support are included. The estimated effects are displayed in Figure 8 (with data from the raw-performance paring condition) and Figure 9 (with data from the contest-performance pairing condition. Both figures suggest that our main findings are robust to changing bandwidth. 
Table 14: Results using cross validation procedure with data from the rawperformance pairing condition. This table displays the estimated effect of winning round 1 on "effort" measures and winning probability in round 2, using the optimally chosen bandwidth for LLR with an Epanechnikov kernel weighting function. Standard errors are constructed by standard bootstrap (2000 replications) and indicated in brackets. Significance at ${ }^{*} 10 \%,{ }^{* *} 5 \%,{ }^{* *} 1 \%$.

\begin{tabular}{|c|c|c|c|c|c|}
\hline & & $\begin{array}{l}\text { Strings } \\
\text { completed }\end{array}$ & $\begin{array}{l}\text { Time } \\
\text { spent }\end{array}$ & Productivity & $\begin{array}{l}\text { Winning } \\
\text { prob. }\end{array}$ \\
\hline \multirow[t]{3}{*}{ Baseline } & Optimal bw & 0.037 & 0.037 & 0.089 & 0.044 \\
\hline & $\hat{\beta}$ & $4.07^{*}$ & $1.84^{*}$ & $0.58^{* *}$ & $0.24^{* * *}$ \\
\hline & se & $(2.44)$ & $(1.03)$ & $(0.29)$ & $(0.09)$ \\
\hline \multirow[t]{3}{*}{ PastInfo } & Optimal bw & 0.041 & 0.010 & 0.041 & 0.010 \\
\hline & $\hat{\beta}$ & 2.82 & 0.31 & $0.25^{*}$ & 0.05 \\
\hline & se & $(1.72)$ & $(0.67)$ & $(0.14)$ & $(0.04)$ \\
\hline \multirow[t]{3}{*}{ PastWinUninformative } & Optimal bw & 0.016 & 0.015 & 0.014 & 0.139 \\
\hline & $\hat{\beta}$ & 1.76 & 1.27 & -0.01 & 0.11 \\
\hline & se & $(2.65)$ & $(1.03)$ & $(0.14)$ & $(0.06)$ \\
\hline
\end{tabular}

Table 15: Results using cross validation procedure with data from the contestperformance pairing condition. This table displays the estimated effect of winning round 1 on "effort" measures and winning probability in round 2, using the optimally chosen bandwidth for LLR with an Epanechnikov kernel weighting function. Standard errors are constructed by standard bootstrap (2000 replications) and indicated in brackets. Significance at ${ }^{*} 10 \%,{ }^{* *} 5 \%,{ }^{* *} 1 \%$.

\begin{tabular}{|c|c|c|c|c|c|}
\hline & & $\begin{array}{l}\text { Strings } \\
\text { completed }\end{array}$ & $\begin{array}{l}\text { Time } \\
\text { spent }\end{array}$ & Productivity & $\begin{array}{l}\text { Winning } \\
\text { prob. }\end{array}$ \\
\hline \multirow[t]{3}{*}{ Baseline } & Optimal bw & 0.420 & 0.016 & 0.354 & 0.056 \\
\hline & $\hat{\beta}$ & $4.33^{* *}$ & $2.33^{* *}$ & $0.30^{*}$ & $0.17^{* * *}$ \\
\hline & se & $(2.01)$ & $(0.94)$ & $(0.16)$ & $(0.06)$ \\
\hline \multirow[t]{3}{*}{ PastInfo } & Optimal bw & 0.037 & 0.146 & 0.037 & 0.219 \\
\hline & $\hat{\beta}$ & 2.28 & 0.69 & 0.09 & $0.08^{* *}$ \\
\hline & se & $(1.43)$ & $(0.55)$ & $(0.08)$ & $(0.03)$ \\
\hline \multirow[t]{3}{*}{ PastWinUninformative } & Optimal bw & 0.075 & 0.041 & 0.057 & 0.074 \\
\hline & $\hat{\beta}$ & -0.07 & 0.16 & 0.06 & 0.02 \\
\hline & se & $(2.07)$ & $(0.89)$ & $(0.15)$ & $(0.06)$ \\
\hline
\end{tabular}


Figure 8: A display of the impact of varying bandwidth on the estimated effect of winning using data from raw-performance pairing.
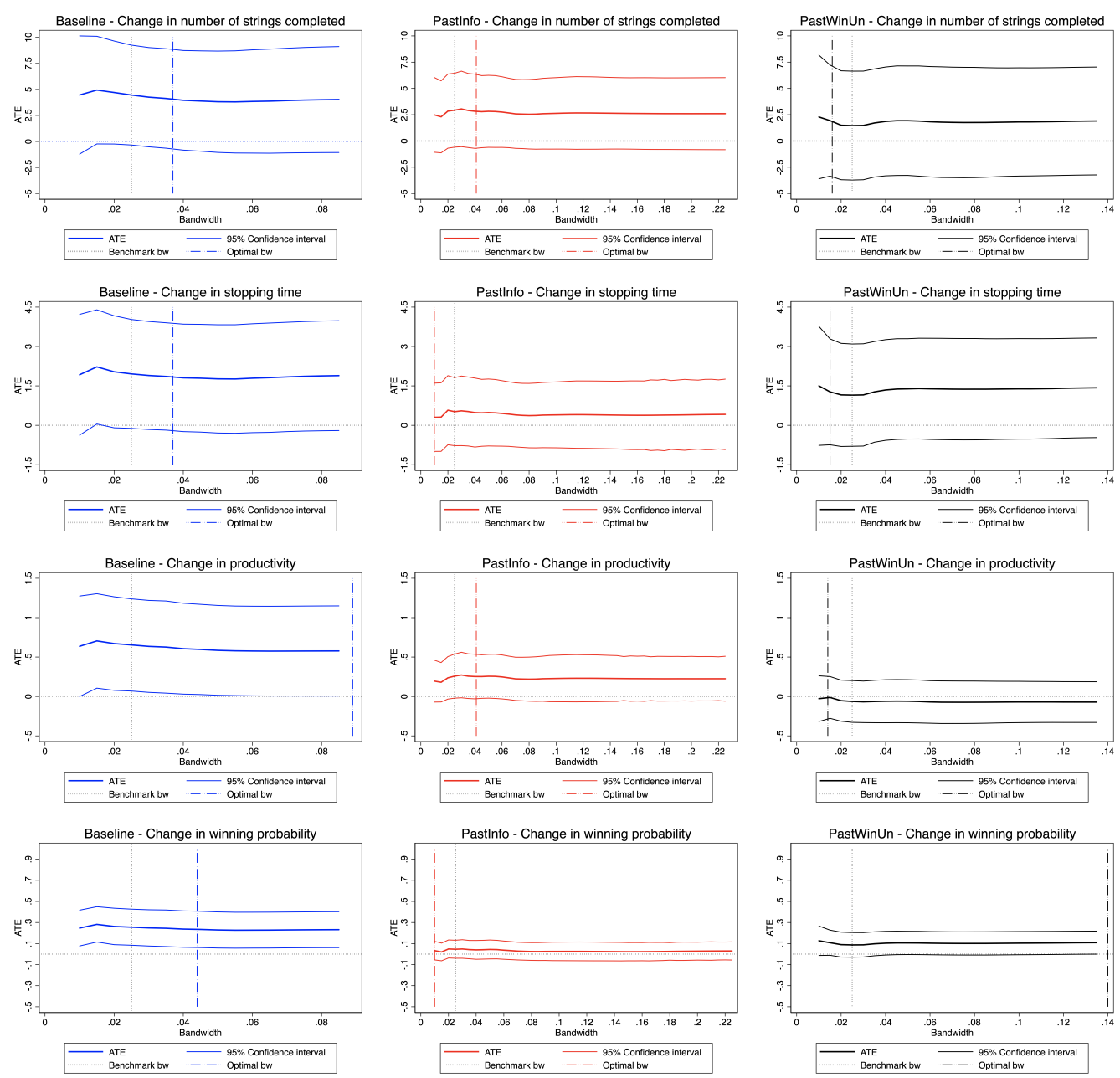
Figure 9: A display of the impact of varying bandwidth on the estimated effect of winning using data from contest-performance pairing.
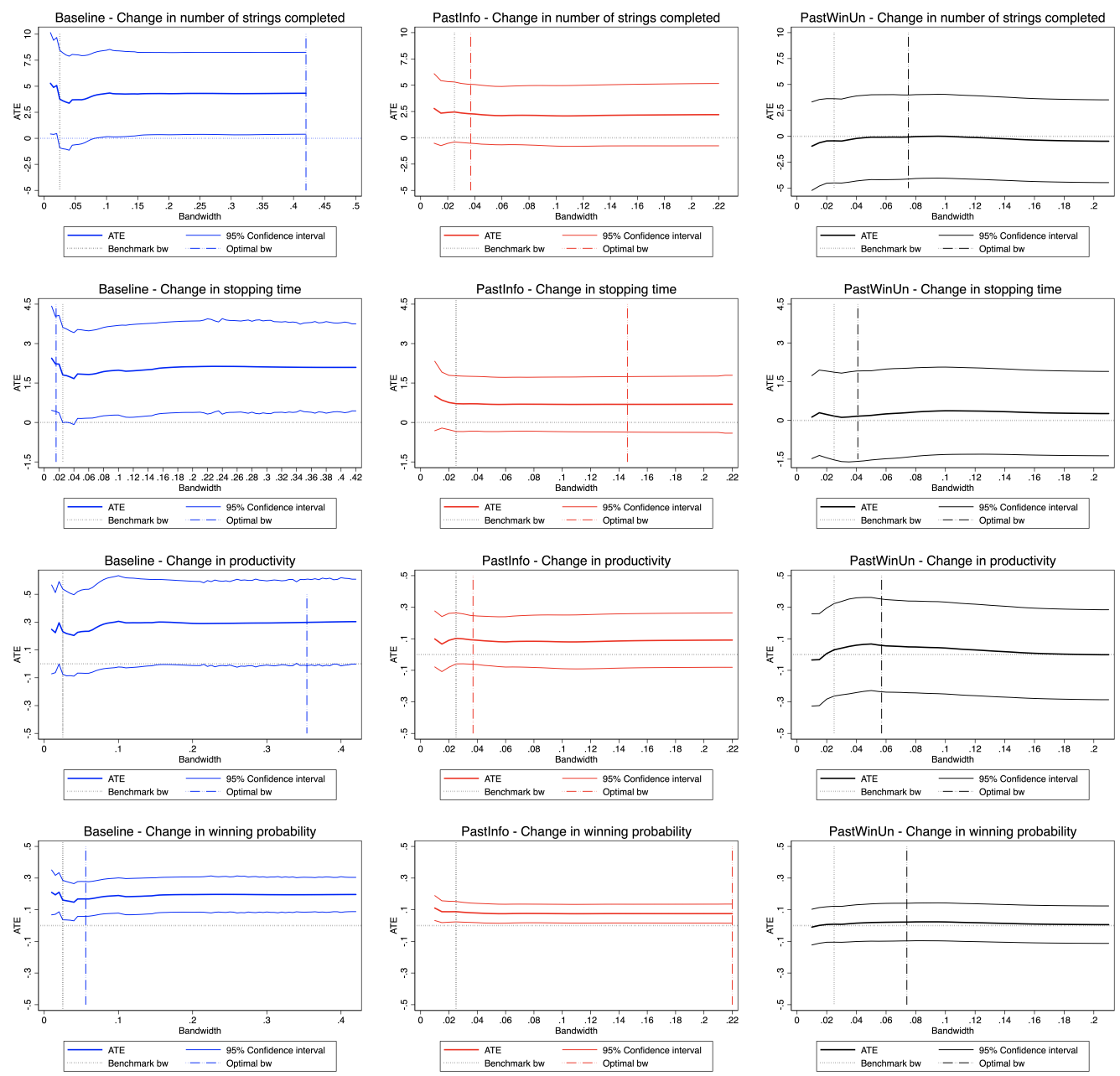
C.4 Re-sampling at the pair level 
Table 16: Effect of winning round 1 on "effort" measures and winning probability in round 2, estimated by LLR matching. For estimates with all observations, the matching is done within each condition. The bandwidth for the LLR is set to 0.025 with an Epanechnikov kernel weighting function. For estimates with all observations, the matching is done within each condition. Standard errors are indicated in brackets and constructed by bootstrap at the pair-level (2000 replications). N is the total number of observations in each treatment and $\mathrm{N}$ (supp.) is the total number of observations on the common support. Significance at ${ }^{*} 10 \%$, ${ }^{*} 5 \%$, $* * * 1 \%$.

\begin{tabular}{|c|c|c|c|c|c|c|}
\hline \multicolumn{7}{|c|}{ Raw-performance pairing } \\
\hline Treatment & $\begin{array}{l}\text { Strings } \\
\text { completed }\end{array}$ & $\begin{array}{l}\text { Time } \\
\text { spent }\end{array}$ & Productivity & $\begin{array}{l}\text { Winning } \\
\text { prob. }\end{array}$ & $\mathrm{N}$ & $\mathrm{N}$ (supp.) \\
\hline \multirow[t]{2}{*}{ Baseline } & $4.46^{*}$ & $1.96^{*}$ & $0.65^{* *}$ & $0.26^{* *}$ & 50 & 32 \\
\hline & $(2.68)$ & $(1.13)$ & $(0.31)$ & $(0.12)$ & & \\
\hline \multirow[t]{2}{*}{ FutureInfo } & 0.30 & 0.28 & -0.03 & 0.02 & 46 & 46 \\
\hline & $(1.54)$ & $(0.71)$ & $(0.10)$ & $(0.06)$ & & \\
\hline \multirow[t]{2}{*}{ PastInfo } & $2.93^{* *}$ & 0.52 & $0.26^{* *}$ & 0.08 & 48 & 46 \\
\hline & $(1.41)$ & $(0.59)$ & $(0.13)$ & $(0.06)$ & & \\
\hline \multirow[t]{2}{*}{ PastWinUn } & 1.46 & 1.15 & -0.06 & 0.09 & 54 & 38 \\
\hline & $(2.18)$ & $(0.92)$ & $(0.13)$ & $(0.08)$ & & \\
\hline \multicolumn{7}{|c|}{ Contest-performance pairing } \\
\hline Treatment & $\begin{array}{l}\text { Strings } \\
\text { completed }\end{array}$ & $\begin{array}{l}\text { Time } \\
\text { spent }\end{array}$ & Productivity & $\begin{array}{l}\text { Winning } \\
\text { prob. }\end{array}$ & $\mathrm{N}$ & $\mathrm{N}$ (supp.) \\
\hline \multirow[t]{2}{*}{ Baseline } & 3.76 & $1.81^{* *}$ & 0.23 & $0.16^{*}$ & 66 & 58 \\
\hline & $(2.50)$ & $(0.90)$ & $(0.19)$ & $(0.09)$ & & \\
\hline \multirow[t]{2}{*}{ FutureInfo } & 1.38 & 0.75 & 0.04 & 0.06 & 58 & 58 \\
\hline & $(1.63)$ & $(0.72)$ & $(0.10)$ & $(0.06)$ & & \\
\hline \multirow[t]{2}{*}{ PastInfo } & $2.46^{*}$ & 0.72 & 0.10 & $0.09^{*}$ & 58 & 54 \\
\hline & $(1.34)$ & $(0.48)$ & $(0.09)$ & $(0.05)$ & & \\
\hline \multirow[t]{2}{*}{ PastWinUn } & -0.44 & 0.17 & 0.03 & 0.01 & 58 & 56 \\
\hline & $(2.28)$ & $(0.88)$ & $(0.16)$ & $(0.09)$ & & \\
\hline \multicolumn{7}{|c|}{ All observations } \\
\hline Treatment & $\begin{array}{l}\text { Strings } \\
\text { completed }\end{array}$ & $\begin{array}{l}\text { Time } \\
\text { spent }\end{array}$ & Productivity & $\begin{array}{l}\text { Winning } \\
\text { prob. }\end{array}$ & $\mathrm{N}$ & $\mathrm{N}$ (supp.) \\
\hline \multirow[t]{2}{*}{ Baseline } & $4.01^{* *}$ & $1.86^{* * *}$ & $0.38^{* *}$ & $0.20^{* * *}$ & 116 & 90 \\
\hline & $(1.83)$ & $(0.69)$ & $(0.17)$ & $(0.07)$ & & \\
\hline \multirow[t]{2}{*}{ FutureInfo } & 0.90 & 0.54 & 0.01 & 0.05 & 104 & 104 \\
\hline & $(1.13)$ & $(0.51)$ & $(0.07)$ & $(0.04)$ & & \\
\hline \multirow[t]{2}{*}{ PastInfo } & $2.67^{* * *}$ & $0.63^{*}$ & $0.17^{* *}$ & $0.08^{* *}$ & 106 & 100 \\
\hline & $(0.95)$ & $(0.37)$ & $(0.08)$ & $(0.04)$ & & \\
\hline \multirow[t]{2}{*}{ PastWinUn } & 0.33 & 0.56 & -0.01 & 0.04 & 112 & 94 \\
\hline & $(1.57)$ & $(0.63)$ & $(0.11)$ & $(0.06)$ & & \\
\hline
\end{tabular}


Table 17: Effect of winning round 1 on elicited confidence in round 2's winning chances and performance, estimated by LLR matching. For estimates with all observations, the matching is done within each condition. For estimates with all observations, the matching is done within each condition. The bandwidth for the LLR is set to 0.025 with an Epanechnikov kernel weighting function. Standard errors are constructed by bootstrap at the pair level (2000 replications) and indicated in brackets. Significance at ${ }^{*} 10 \%,{ }^{* *} 5 \%,{ }^{* *} 1 \%$.

\begin{tabular}{|c|c|c|c|}
\hline \multicolumn{4}{|c|}{ Raw performance pairing } \\
\hline Treatment & Win. chances & Performance & $\mathrm{N}$ \\
\hline Baseline & $\begin{array}{l}18.58^{* * *} \\
(4.04)\end{array}$ & & 50 \\
\hline FutureInfo & $\begin{array}{l}9.96^{* *} \\
(3.96)\end{array}$ & & 46 \\
\hline PastInfo & $\begin{array}{l}14.76^{* *} \\
(6.53)\end{array}$ & & 48 \\
\hline PastWinUninformative & $\begin{array}{l}7.23 \\
(5.40)\end{array}$ & & 54 \\
\hline \multicolumn{4}{|c|}{ Contest performance pairing } \\
\hline Treatment & Win. chances & Performance & $\mathrm{N}$ \\
\hline Baseline & $\begin{array}{l}21.58^{* * *} \\
(3.95)\end{array}$ & $\begin{array}{l}19.47^{* * *} \\
(3.66)\end{array}$ & 66 \\
\hline FutureInfo & $\begin{array}{l}13.14^{* * *} \\
(3.49)\end{array}$ & $\begin{array}{l}8.28^{* *} \\
(3.37)\end{array}$ & 58 \\
\hline PastInfo & $\begin{array}{l}17.51^{* * *} \\
(5.22)\end{array}$ & $\begin{array}{l}13.48^{* * *} \\
(4.76)\end{array}$ & 58 \\
\hline PastWinUninformative & $\begin{array}{l}12.01^{* *} \\
(5.01)\end{array}$ & $\begin{array}{l}-0.24 \\
(7.18)\end{array}$ & 58 \\
\hline \multicolumn{4}{|c|}{ All observations } \\
\hline Treatment & Win. chances & Performance & $\mathrm{N}$ \\
\hline Baseline & $\begin{array}{l}20.52^{* * *} \\
(2.81)\end{array}$ & & 116 \\
\hline FutureInfo & $\begin{array}{l}11.73^{* * *} \\
(2.59)\end{array}$ & & 104 \\
\hline PastInfo & $\begin{array}{l}16.24^{* * *} \\
(4.05)\end{array}$ & & 106 \\
\hline PastWinUninformative & $\begin{array}{l}10.08^{* *} \\
(3.08)\end{array}$ & & 112 \\
\hline
\end{tabular}




\section{Looking at behaviour in round 3}

Our identification strategy is designed to study what happens in round 2, by matching on winning probability in round 1 . One could be tempted to use the observations in round 3 to also investigate the existence of a momentum. We explain here why round 3 observations do not allow us to identify cleanly a momentum. For this reason we only provide summary statistics of the round 3 observations in Table 7 and 8.

Matching not possible: Our matching approach cannot be used to look at round 3 behaviour. The reason is simple, the matching is intended to compare two players with similar past performance but different histories of winning. In round 2, matching on the probability of winning in round 1 achieves these two goals. Matched players indeed had similar past performance (equal winning probabilities) but they had different outcomes in the round 1 (win/loss).

We cannot achieve the same two goals in round 3 by matching winners and losers in round 2 with similar winning probabilities. The matching would compare players with similar performance in round 2 , but it would not control for differences in performance in round 1. By design of the best-of-three contest, the performances in round 2 will systematically vary with the outcome in round 1 . To reach the round 3 , winners in round 2 must have lost in round 1, losers in round 2 must have won in round 1. Even though matching may control for the performance in round 2, the players would still systematically differ in their round 1 performance.

Simple comparison of past winner/loser has hidden selection: Another approach has been suggested to use round 3 observations to study a psychological momentum. Both Malueg and Yates (2010) and Mago, Sheremeta and Yates (2013) looked at round 3 when both players have won a round (1-1) and compared the winner in round 2 to the loser in round 2 . This approach is similar to a matching on round 2 performance with a large bandwidth (e.g. $100 \%$ ) such that all winners are compared to all losers.

This approach faces the same issue as described above. It relies on the assumption that players are perfectly homogeneous in ability to start with. If so, they have then identical characteristics in 1-1, independently of their past performance (win-loss or loss-win). As there should not be any strategic momentum in 1-1, any momentum can be seen as a sign of psychological momentum. However, whenever unobserved differences exist between players, there is no reason to expect that players who won and then loss have on average the same ability as players who lost and then won.

Players who caught back in a second round may had to overcome momentum against them. They may be stronger on average than players who lost an early advantage while benefiting from a momentum. This hidden selection creates a bias which 
can create a spurious momentum in 1-1. For this reason, in spite of their apparent symmetric appeal, the 1-1 situations do not provide an good setting to cleanly isolate a momentum effect in a best-of-three contest. 
E Instructions: raw-performance pairing 


\section{E.1 Instructions for the evaluation stage}

Welcome to our experiment! You will receive AUD 5 for showing up on time. Please read these instructions carefully and completely. Properly understanding the instructions will help you to make better decisions and, hence, to earn more money. If you read these instructions carefully and perform well in the experiment, you can earn a significant amount of money (which will be paid out to you in cash at the end of the experiment).

Please keep in mind that you are not allowed to communicate with other participants during the experiment. You are not allowed to use your mobile phone at any time either. If you do not obey these rules you will be asked to leave the laboratory and will not be paid. Whenever you have a question, please raise your hand; an experimenter will come to assist you.

This experiment consists of two parts. You will receive separate instructions for each part. Your final payment will be the sum of your earnings in both parts, plus your show-up fee.

\section{Part 1}

In this experiment you will be asked to reverse strings of characters that will appear on your screen. Each string is randomly generated and has 20 characters.

For example, if you see:

\section{NvpXEu39GXBvaBTqUirj}

You have to enter:

\section{jriUqTBavBXG93uEXpvN}

You will be doing this task for 10minutes. For each string you correctly reverse you will get $20 \mathrm{cts}$. A typical screen that you will be seeing is as follows:

\section{Practice Round}

Time left to complete this page: $\odot 0: 55$

This is the string you have to reverse:

NvpXEu39GXBvaBTqUir

Your payoff will be computed as follows:

Number of tasks completed correctly $\times 20 \mathrm{cts}$

For instance, if you completed 8 tasks, you will earn: $8 \times$ AUD $0.2=$ AUD 1.6.

To make sure that you understand the task and know how to work, you will have the opportunity to practice for 1 minute without payment. 


\section{E.2 Instructions for best-of-three contests}

\section{$\underline{\text { Part } 2 \text { (for Baseline treatment) }}$}

\section{Matching}

In this part, the computer will rank all the participants in this session according to the number of tasks completed in Part 1. Then it will match the two participants with the closest ranks into a pair.

For instance, a participant with rank 1 will be paired with a participant with rank 2 , and a participant with rank 3 will be paired with the one in rank 4 , etc.

The ranking and pairing assignments remain anonymous throughout the entire experiment. You will not be informed about the identity of the participant in this room you have been paired with. You will also not be able to learn your actual rank or the rank of anyone else. All you should keep in mind is that your opponent has the closest rank to you (based on performance records from Part 1).

\section{Competition}

In this part, the two participants in a pair will compete against each other. The competition consists of maximum three independent rounds. The one who wins two out of the three rounds wins the competition and will be awarded a prize of AUD 20.

The competition in each round is organized as follows: both you and your competitor will work simultaneously and independently on the same 10-minute task as in Part 1.You will NOT learn how many tasks you or your opponent has completed during the competition. Nonetheless, the more tasks you complete, the more likely you are to win in each round.

The winner of each round is determined according to the following procedure:

Imagine that you are facing an urn. Each time you complete a task correctly, you earn one black ball that will go into the urn. Each time your competitor completes a task correctly, he/she earn a white ball that goes into the urn. At the end of the round, the computer randomly picks a ball from the urn. If it is black you win that round, if it is white your competitor wins that round. This procedure is depicted in the following figure.

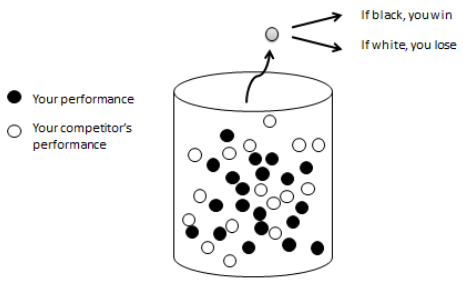

This means that your probability to win a round depends on both your performance and your competitor's performance in that round. Specifically, it is computed as:

Your Probability to win $=\frac{\text { total number of tasks completed correctly by you }}{\text { total number of tasks completed by you and your competitor }}$ 
For example, if you and your competitor complete equal number of tasks (including if you both solve 0 tasks) you have $50 \%$ chance of winning. If you solve more (or less) tasks than your competitor, you have more than (or less than) $50 \%$ chance to win.

\section{Time is money}

Spending time to work on the tasks in this competition is costly. In each round, you are endowed with AUD 3. As soon as you enter a round, your endowment starts depleting. You pay AUD 0.005 (i.e., half a cent) per second for the time you spend working on the tasks. You are free to stop working at any point during the competition though. Once you decide that you have worked enough for the competition, you could simply click the "STOP" button displayed at the right-bottom of the screen (see the screen shot below).

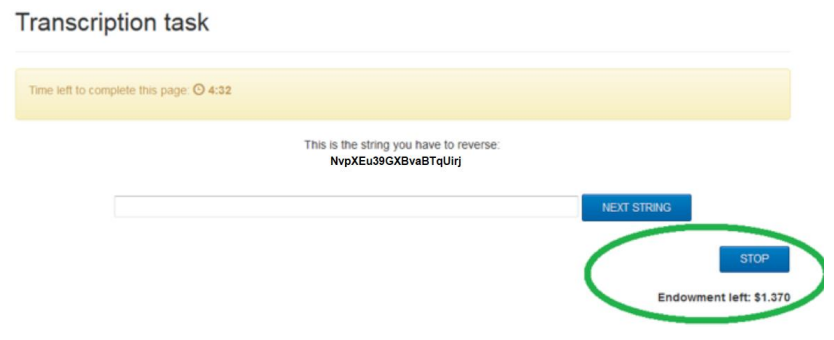

All the tasks you completed correctly before hitting the Stop button will be accounted for, when the winner is determined (i.e., the black balls you have earned stay in the urn).

For instance, if you stop as soon as the round starts, you will receive the full endowment AUD 3 for that round, but you will lose that round for sure if your competitor completes at least one task correctly; If you work for 5 minutes ( 300 seconds) and then press the Stop button, your initial endowment will be reduced by: AUD 1.50 (=300 x AUD 0.005) and the remaining endowment will be included in your final payment; At the same time, your chance of winning that round is determined by the total number of tasks you have completed correctly within that 5 minutes, together with the total number of tasks your competitor has completed.

Please note that once the "stop" button is hit, you cannot come back to the task anymore.

Remember that you will not see the number of correct tasks completed by you and your competitor during each round. This is also true when the round is finished. However, you will be informed who the winner is at the end of each round. After two rounds of competition, if you and your competitor each have won one round, you will need to compete in a third round to break the tie. The competition in the third round works the same as in the first and second round and the winner of the third round receives the prize. If you have won (or lost) both rounds, you have won (or lost) the prize. There is no need to compete in the third round. Nevertheless, you will receive the full endowment AUD 3 for that round, as you will not spend any time in competing. 


\section{After the competition}

After everyone in this room has finished the competition, you will need to finish a simple exit questionnaire. All the information you provide in this questionnaire, as well as your performance data in the experiment will only be used for statistical analysis and will be kept anonymous and strictly confidential.

Once the questionnaire is done, your total payment from this experiment will be calculated as the following:

If you win:

Total payment $=$ show-up fee $(A U D 5)+$ earnings from Part $1+$ prize $(A U D 20)+$ total endowment you kept in all three rounds

If you lose:

Total payment=show-up fee (AUD 5) + earnings from Part $1+$ total endowment you kept in all three rounds

At the end of this session, your performance and your competitor's performance in each round, as well as your payoff will be displayed to you. See the following screenshot as an example.

\begin{tabular}{cccccc}
\multicolumn{7}{c}{$\begin{array}{c}\text { The participation fee is } \$ 5 . \\
\text { Your total payoffs are: } \$ 22.45\end{array}$} & \\
Summary & & & \\
\hline $\begin{array}{c}\text { Round } \\
\text { number }\end{array}$ & $\begin{array}{c}\text { Your } \\
\text { performance }\end{array}$ & $\begin{array}{c}\text { Your opponent's } \\
\text { performance }\end{array}$ & $\begin{array}{c}\text { Number of } \\
\text { wins }\end{array}$ & $\begin{array}{c}\text { Time left on } \\
\text { counter }\end{array}$ & Payoff \\
\hline Part 1 & 9 & NA & NA & NA & $\$ 2.25$ \\
\hline Part 2-round1 & 0 & 3 & 0 & 39 & $\$ 0.20$ \\
\hline Part 2-round2 & 10 & 0 & 1 & 0 & $\$ 0.00$ \\
\hline Part 2-round3 & 13 & 9 & 2 & 0 & $\$ 20.00$ \\
\hline
\end{tabular}

\section{Part 2 (for FutureInfo treatment)}

\section{Matching}

In this part, the computer will rank all the participants in this session according to the number of tasks completed in the first round of Part 1 . Then it will match the two participants with the closest ranks into a pair.

For instance, a participant with rank 1 will be paired with a participant with rank 2, and a participant with rank 3 will be paired with the one in rank 4, etc.

The ranking and pairing assignments remain anonymous throughout the entire experiment. You will not be informed about the identity of the participant in this room you have been paired with. You will also 
not be able to learn your actual rank or the rank of anyone else. All you should keep in mind is that your competitor has the closest rank to you (based on performance records from Part 1).

\section{Competition}

In this part, the two participants in a pair will compete against each other. The competition consists of maximum three independent rounds. The one who wins two out of the three rounds wins the competition and will be awarded a prize of AUD 20.

In round 1 , the winner is decided by a rolling die. First, the computer will randomly assign you and your competitor to odd numbers and even numbers respectively. And then the computer will throw a rolling die (with numbers 1, 2, 3, 4, 5, 6 on each side of the die). If the number showing up on the die is an odd number (either 1 , or 3 , or 5 ), then the one who has been assigned to odd numbers will win round 1 ; if the number showing up on the die is an even number (either 2 , or 4 , or 6 ), then the one who has been assigned to even numbers will win round 1 .

In round 2 and 3, both you and your competitor will work simultaneously and independently on the same 10-minute task as in Part 1. You will NOT learn how many tasks you or your competitor has completed during the competition. Nonetheless, the more tasks you complete, the more likely you are to win in each round.

The winner of each round is determined according to the following procedure:

Imagine that you are facing an urn. Each time you complete a task correctly, you earn one black ball that will go into an urn. Each time your competitor completes a task correctly, he/she earn a white ball that goes into the urn. At the end of the round, the computer randomly picks a ball from the urn. If it is black you win that round, if it is white your competitor wins that round. This procedure is depicted in the following figure.

- Your performance Your competitors performance

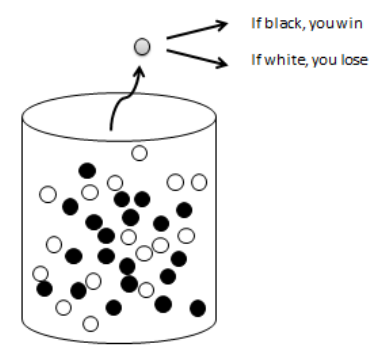

This means that your probability to win a round depends on both your performance and your competitor's performance in that round. Specifically, it is computed as: 
Your Probability to win $=\frac{\text { total number of tasks completed correctly by you }}{\text { total number of tasks completed by you and your competitor }}$

For example, if you and your competitor complete equal number of tasks (including if you both solve 0 tasks) you have $50 \%$ chance of winning. If you solve more (or less) tasks than your competitor, you have more than (or less than) $50 \%$ chance to win.

\section{Time is money}

Spending time to work on the tasks in this competition is costly. In round 2 and 3, you are endowed with AUD 3. As soon as you enter a round, your endowment starts depleting. You pay AUD 0.005 (i.e., half a cent) per second for the time you spend working on the tasks. You are free to stop working at any point during the competition though. Once you decide that you have worked enough for the competition, you could simply click the "STOP" button displayed at the right-bottom of the screen (see the screen shot below).

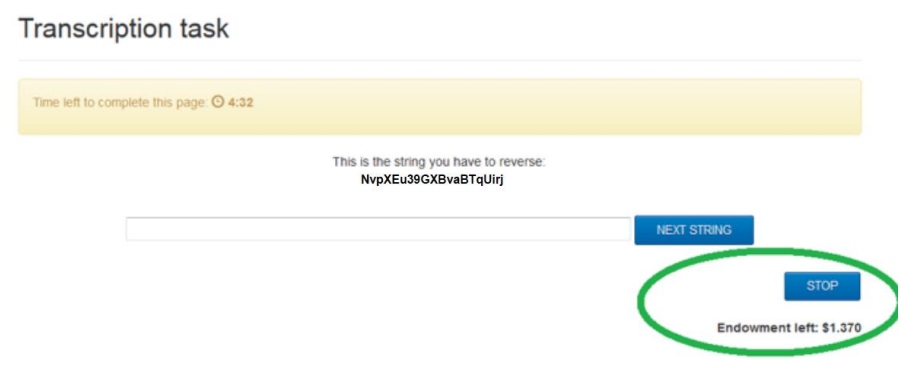

All the tasks you completed correctly before hitting the Stop button will be accounted for, when the winner is determined (i.e., the black balls you have earned stay in the urn).

For instance, if you stop as soon as the round starts, you will receive the full endowment AUD 3 for that round, but you will lose that round for sure if your competitor completes at least one task correctly; If you work for 5 minutes ( 300 seconds) and then press the Stop button, your initial endowment will be reduced by: AUD 1.50 (=300 x AUD 0.005) and the remaining endowment will be included in your final payment; At the same time, your chance of winning that round is determined by the total number of tasks you have completed correctly within that 5 minutes, together with the total number of tasks your competitor has completed.

Please note that once the "stop" button is hit, you cannot come back to the task anymore.

Remember that you will not see the number of correct tasks completed by you and your competitor during each round. This is also true when the round is finished. However, you will be informed who the winner is at the end of each round. After two rounds of competition, if you and your competitor each have won one round, you will need to compete in a third round to break the tie. The competition in the third round works the same as in the second round and the winner of the third round receives the prize. If you have 
won (or lost) round 1 and round 2, you have won (or lost) the prize. There is no need to compete in the third round. Nevertheless, you will receive the full endowment AUD 3 for that round, as you will not spend any time in competing.

\section{After the competition}

After everyone has finished the competition, you will need to finish a simple exit questionnaire. All the information you provide in this questionnaire, as well as your performance data in the experiment will only be used for statistical analysis and will be kept anonymous and strictly confidential.

Once the questionnaire is done, your total payment from this experiment will be calculated as follows:

If you win:

Total payment $=$ show-up fee $($ AUD 5) + earnings from Part $1+$ prize $(A U D 20)+$ total endowment you kept round 2 and 3

If you lose:

Total payment=show-up fee $(A U D 5)+$ earnings from Part $1+$ total endowment you kept round 2 and 3

At the end of this session, your performance and your competitor's performance in each round, as well as your payoff will be displayed to you. See the following screenshot as an example.

\begin{tabular}{|c|c|c|c|c|c|}
\hline & & $\begin{array}{l}\text { The participation fe } \\
\text { Your total payoffs are }\end{array}$ & 8.96 & & \\
\hline Round number & $\begin{array}{c}\text { Your } \\
\text { performance }\end{array}$ & $\begin{array}{l}\text { Your competitor's } \\
\text { performance }\end{array}$ & $\begin{array}{l}\text { Number of } \\
\text { wins }\end{array}$ & $\begin{array}{l}\text { Time left on counter } \\
\text { (in s.) }\end{array}$ & Payoff \\
\hline Part 1 - Round 1 & 9 & 6 & - & - & 1.80 \\
\hline Part 1 - Round 2 & 6 & 8 & - & - & 1.20 \\
\hline $\begin{array}{l}\text { Part } 2 \text { - Round } 1 \\
\text { (die) }\end{array}$ & $\cdot$ & $\cdot$ & 1 & $\cdot$ & $\cdot$ \\
\hline Part 2 - Round 2 & 1 & 9 & 2 & 591 & $\$ 22.96$ \\
\hline Part 2 - Round 3 & - & - & - & - & $\$ 3.00$ \\
\hline
\end{tabular}

\section{Part 2 (for PastInfo \& PastWinUninformative treatments)}

\section{Matching}

In this part, the computer will rank all the participants in this session according to the number of tasks completed in Part 1. Then it will match the two participants with the closest ranks into a pair.

For instance, a participant with rank 1 will be paired with a participant with rank 2, and a participant with rank 3 will be paired with the one in rank 4, etc.

The ranking and pairing assignments remain anonymous throughout the entire experiment. You will not be informed about the identity of the participant in this room you have been paired with. You will also not be able to learn your actual rank or the rank of anyone else. All you should keep in mind is that your opponent has the closest rank to you (based on performance records from Part 1). 


\section{Competition}

In this part, the two participants in a pair will compete against each other. The competition consists of maximum three independent rounds. The one who wins two out of the three rounds wins the competition and will be awarded a prize of AUD 20.

The competition in the first two rounds is organized as follows: both you and your competitor will work simultaneously and independently on the same 10-minute task as in Part 1. [PastInfo: You will NOT learn how many tasks you or your opponent has completed during the competition.] Nonetheless, the more tasks you complete, the more likely you are to win in each round.

The winner of round 1 and round 2 is determined according to the following procedure:

Imagine that you are facing an urn. Each time you complete a task correctly, you earn one black ball that will go into the urn. Each time your competitor completes a task correctly, he/she earn a white ball that goes into the urn. At the end of the round, the computer randomly picks a ball from the urn. If it is black you win that round, if it is white your competitor wins that round. This procedure is depicted in the following figure.

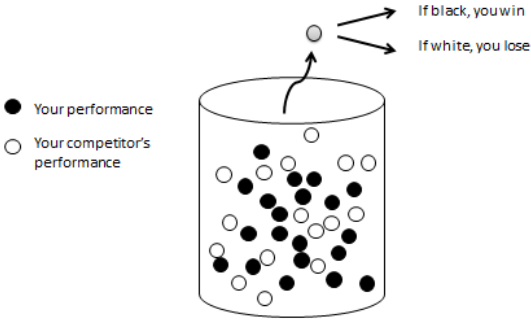

This means that your probability to win a round depends on both your performance and your competitor's performance in that round. Specifically, it is computed as:

$$
\text { Your Probability to win }=\frac{\text { total number of tasks completed correctly by you }}{\text { total number of tasks completed by you and your competitor }}
$$

For example, if you and your competitor complete equal number of tasks (including if you both solve 0 tasks) you have $50 \%$ chance of winning. If you solve more (or less) tasks than your competitor, you have more than (or less than) $50 \%$ chance to win.

\section{Time is money}

Spending time to work on the tasks in this competition is costly. In the first two rounds, you are endowed with AUD 3 for each round. As soon as you enter a round, your endowment starts depleting. You pay 
AUD 0.005 (i.e., half a cent) per second for the time you spend working on the tasks. You are free to stop working at any point during the competition though.

Once you decide that you have worked enough for the competition, you could simply click the "STOP" button displayed at the right-bottom of the screen (see the screen shot below).

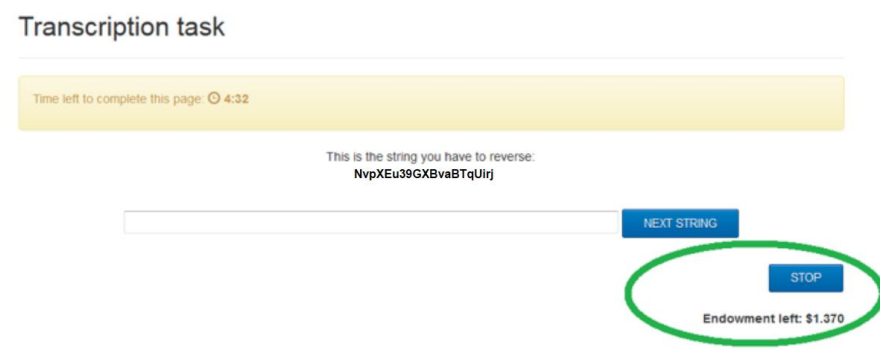

All the tasks you completed correctly before hitting the Stop button will be accounted for, when the winner is determined (i.e., the black balls you have earned stay in the urn).

For instance, if you stop as soon as the round starts, you will receive the full endowment AUD 3 for that round, but you will lose that round for sure if your competitor completes at least one task correctly; If you work for 5 minutes (300 seconds) and then press the Stop button, your initial endowment will be reduced by: AUD 1.50 (=300 x AUD 0.005) and the remaining endowment will be included in your final payment; At the same time, your chance of winning that round is determined by the total number of tasks you have completed correctly within that 5 minutes, together with the total number of tasks your competitor has completed.

Please note that once the "stop" button is hit, you cannot come back to the task anymore.

\section{Tie breaking rule}

[PastInfo: Remember that you will not see the number of correct tasks completed by you and your competitor during each round. This is also true when the round is finished. However, you will be informed who the winner is at the end of each round.]

[PastWinUninformative: You will learn whether you won at the end of each round.]

After two rounds of competition, if you have won (or lost) both rounds, you have won (or lost) the prize. There is no need to compete in the third round. However, if you and your competitor each have won one round, you will enter a third round to break the tie and the winner of the third round receives the prize.

In the third round, the computer will first randomly assign you and your opponent to odd numbers and even numbers respectively. And then the computer will throw a rolling die (with numbers 1, 2, 3, 4, 5, 6 on each side of the dice). If the number showing up on the die is an odd number (either 1 , or 3 , or 5 ), then the one who has been assigned to odd numbers will win round 3; if the number showing up on the dice is an even number (either 2 , or 4 , or 6 ), then the one who has been assigned to even numbers will win round 3 . The winner in this round will be awarded the prize. 


\section{After the competition}

After everyone has finished the competition, you will need to finish a simple exit questionnaire. All the information you provide in this questionnaire, as well as your performance data in the experiment will only be used for statistical analysis and will be kept anonymous and strictly confidential.

Once the questionnaire is done, your total payment from this experiment will be calculated as the following:

If you win:

Total payment $=$ show-up fee $(A U D 5)+$ earnings from Part $1+$ prize $(A U D 20)+$ total endowment you kept

If you lose:

Total payment=show-up fee (AUD 5) + earnings from Part $1+$ total endowment you kept

At the end of this session, your performance and your competitor's performance in each round, as well as your payoff will be displayed to you. See the following screenshot as an example.

\begin{tabular}{cccccc} 
& \multicolumn{1}{c}{$\begin{array}{c}\text { The participation fee is } \$ 5 . \\
\text { Your total payoffs are: } \$ 22.73\end{array}$} & & & \\
\hline $\begin{array}{c}\text { Round } \\
\text { number }\end{array}$ & $\begin{array}{c}\text { Your } \\
\text { performance }\end{array}$ & $\begin{array}{c}\text { Your competitor's } \\
\text { performance }\end{array}$ & $\begin{array}{c}\text { Number of } \\
\text { wins }\end{array}$ & $\begin{array}{c}\text { Time left on counter } \\
\text { (in s.) }\end{array}$ & Payoff \\
\hline Part 1 & 5 & - & - & - & $\$ 1.00$ \\
\hline $\begin{array}{c}\text { Part } \\
\text { 2-round1 }\end{array}$ & 5 & 5 & 1 & 0.0 & $\$ 0.00$ \\
\hline $\begin{array}{c}\text { Part } \\
\text { 2-round2 }\end{array}$ & 5 & 3 & 1 & 346.0 & $\$ 1.73$ \\
\hline $\begin{array}{c}\text { Part } \\
\text { 2-round3 }\end{array}$ & - & - & 2 & - & $\$ 20.00$ \\
\hline
\end{tabular}


F Instructions: contest-performance pairing 


\section{F.1 Instructions for the evaluation stage}

Welcome to our experiment! You will receive AUD 10 for showing up on time. Please read these instructions carefully and completely. Properly understanding the instructions will help you to make better decisions, and hence earn more money. Your earnings will be paid out to you in cash at the end of the experiment.

Please keep in mind that you are not allowed to communicate with other participants during the experiment. You are not allowed to use your mobile phone at any time either. If you do not obey these rules you will be asked to leave the laboratory and will not be paid. Whenever you have a question, please raise your hand and an experimenter will come to assist you.

This experiment consists of several parts. You will receive separate instructions for each part. Your final payment will be the sum of your earnings from all parts, plus your show-up fee (AUD 10).

\section{Part 1}

\section{Competition}

In this part of the experiment, the computer will randomly pair you with another participant in this room. The pairing will remain anonymous throughout the entire experiment. You will not be informed about the identity of the participant you have been paired with.

You will then be asked to individually reverse strings of characters that will appear on your screen. Each string is randomly generated and has 20 characters.

For example, if you see:

\section{NvpXEu39GXBvaBTqUirj}

You have to enter:

$$
\text { jriUqTBavBXG93uEXpvN }
$$

You will be working on this task independently for a maximum of 10 minutes. You will have the option to stop working at any point during these 10 minutes. If you decide you have worked enough, you can simply click the "STOP" button displayed at the bottom-right of the screen (see the screenshot below). You will NOT learn how many strings you or your competitor have completed during the competition. Nonetheless, the more strings you complete correctly, the more likely you are to win a prize of AUD 7. 


\section{Transcription task}

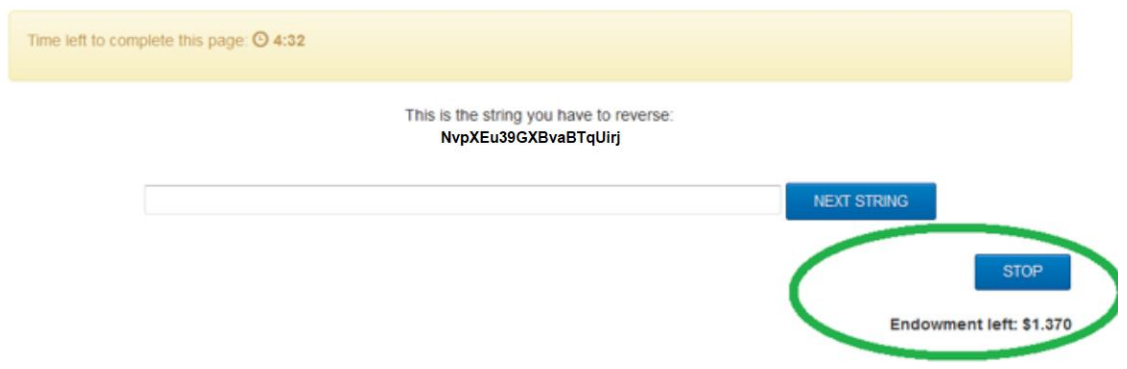

The winner of this part is determined according to the following procedure:

Imagine that you are facing an urn. Each time you complete a task correctly, you earn one black ball that will go into the urn. Each time your competitor completes a task correctly, he/she earns a white ball that goes into the urn. At the end of the round, the computer randomly picks a ball from the urn. If it is black you win that round, if it is white your competitor wins that round. This procedure is depicted in the following figure.

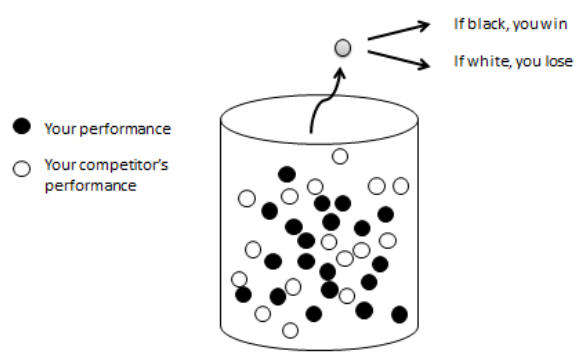

This means that your probability to win depends on both your performance and your competitor's performance in this part. Specifically, it is computed as:

Your Probability to win

total number of tasks completed correctly by you

$=\overline{\text { total number of tasks completed correctly by you and your competitor }}$

For example, if you and your competitor complete equal number of tasks (including if you both solve 0 tasks) you have $50 \%$ chance of winning. If you solve more (or less) tasks than your competitor, you have more than (or less than) $50 \%$ chance to win.

\section{Time is money}

Spending time to work on the tasks in this competition is costly. At the beginning of this competition, you are endowed with AUD 3. As soon as you begin to reverse the strings, your 
endowment starts depleting. You pay AUD 0.005 (i.e., half a cent) per second for the time you spend working on the tasks. You are free to stop working at any point during the competition though. Once you decide that you have worked enough for the competition, you could simply click the "STOP" button displayed at the right-bottom of the screen (see the screen shot above).

All the tasks you completed correctly before hitting the "STOP" button will be accounted for when the winner is determined (i.e., the black balls you have earned stay in the urn).

For instance, if you stop as soon as the round starts, you will receive the full endowment AUD 3 for that round, but you will lose that round for sure if your competitor completes at least one task correctly; If you work for 5 minutes (300 seconds) and then press the "STOP" button, your initial endowment will be reduced by: AUD 1.50 (=300 x AUD 0.005) and the remaining endowment will be included in your final payment; At the same time, your chance of winning that round is determined by the total number of tasks you have completed correctly within that 5 minutes, together with the total number of tasks your competitor has completed correctly.

Please note that once the "STOP" button is hit, you cannot go back to the task anymore.

Remember that you will not see the number of correct tasks completed by you or your competitor during competition. This is also true when you finish the competition. This information, together with the winner selected by the computer will be revealed to you at the end of today's experiment.

\section{Your earnings}

Your payoff for this part will be calculated as follows:

If you win:

Your earnings $=$ prize $(A U D 7)+$ endowment kept $(=$ remaining time $*$ AUD 0.005)

If you lose:

Your earnings $=0+$ endowment kept $(=$ remaining time $*$ AUD 0.005)

To make sure that you understand the task and know how to compete, you will first have the opportunity to practice on the task for 1 minute without payment and then answer a couple of questions about the instructions for this part. 


\section{F.2 Instructions for best-of-three contests}

\section{$\underline{\text { Part } 2 \text { (for Baseline treatment) }}$}

\section{Matching}

In this part, the computer will rank all the participants in this session according to the number of tasks completed correctly in Part 1 . Then it will match the two participants with the closest ranks into a pair. For instance, a participant with rank 1 will be paired with a participant with rank 2, and a participant with rank 3 will be paired with the one in rank 4, etc.

The ranking and pairing assignments remain anonymous throughout the entire experiment. You will not be informed about the identity of the participant in this room you have been paired with. You will also not be able to learn your actual rank or the rank of anyone else. All you should keep in mind is that your competitor has the closest rank to you (based on performance records from Part 1).

\section{Competition}

In this part, the competition between you and your newly paired competitor consists of a maximum of three independent rounds. Whoever wins two out of the three rounds first wins the competition and will be awarded a prize of AUD 20.

The competition in each round follows the same procedure as the competition in Part 1: both you and your competitor will work simultaneously and independently for a maximum of 10 minutes on the same string-reversion task. For each of these three rounds, you are endowed with AUD 3. As soon as you begin to reverse the strings, your endowment starts depleting. You pay AUD 0.005 (i.e., half a cent) per second for the time you spend working on the tasks. You are free to stop working at any point during the competition though. You will NOT learn how many tasks you or your opponent has completed during the competition. Nonetheless, the more tasks you complete correctly, the more likely you are to win in each round. The winner of each round is determined according to the same procedure as well.

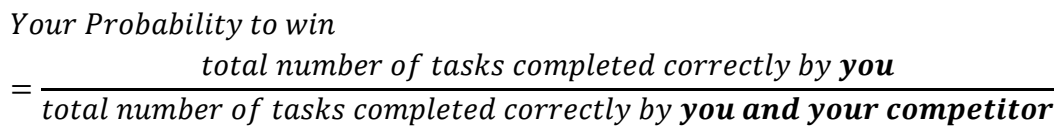

You will be informed who the winner is at the end of each round.

At the end of round 2, If you have won (or lost) both rounds, you have won (or lost) the prize. There is no need to compete in the third round. You will still receive the full initial endowment AUD 3 for that round, as you will not spend any time working on the task. However, if you and your competitor each have won one round after two rounds, you will need to compete in a third round to break the tie. The competition in the third round works the same as in the first and second round and the winner of the third round receives the prize.

\section{Your earnings}


Your payment in Part 2 will be calculated as the following:

If you win:

Your earnings $=$ prize $(A U D 20)+$ total endowment you kept in all three rounds

If you lose:

Your earnings $=0+$ total endowment you kept in all three rounds

After everyone in this room has finished the competition, you will need to answer a few more questions to finish the experiment. All the information you provide in these questions, as well as your performance data in the experiment will only be used for statistical analysis and will be kept anonymous and strictly confidential.

At the end of today's session, your performance and your competitor's performance in every competition, as well as your payoffs will be displayed to you. To make sure you understand the instructions clearly, you will be asked to answer a couple of questions before we start this part of the experiment.

\section{Part 2 (for FutureInfo treatment)}

\section{Matching}

In this part, the computer will rank all the participants in this session according to the number of tasks completed correctly in the first competition in Part 1. Then it will match the two participants with the closest ranks into a pair. For instance, a participant with rank 1 will be paired with a participant with rank 2 , and a participant with rank 3 will be paired with the one in rank 4 , etc.

The ranking and pairing assignments remain anonymous throughout the entire experiment. You will not be informed about the identity of the participant in this room you have been paired with. You will also not be able to learn your actual rank or the rank of anyone else. All you should keep in mind is that your opponent has the closest rank to you (based on performance records from the first competition in Part 1).

\section{Competition}

In this part, the competition between you and your newly paired competitor consists of a maximum of three independent rounds. Whoever wins two out of the three rounds first wins the competition and will be awarded a prize of AUD 20.

The computer will randomly draw a winner in the first round. You could imagine the random draw process as the following: the computer will first randomly assign you and your opponent to odd and even numbers, respectively. And then the computer will throw a rolling die (with numbers $1,2,3,4,5,6$ on each side of the dice). If the number showing up on the die is an odd number (either 1 , or 3 , or 5 ), then who has been assigned to odd numbers will win round $\mathbf{1}$; if 
the number showing up on the dice is an even number (either 2 , or 4 , or 6 ), then who has been assigned to even numbers will win round 1.

After that, the competitions in round 2 and round 3 follows the same procedure as the competition in Part 1: both you and your competitor will work simultaneously and independently for a maximum of 10 minutes on the same string-reversion task. For each of these two rounds, you are endowed with AUD 3. As soon as you begin to reverse the strings, your endowment starts depleting. You pay AUD 0.005 (i.e., half a cent) per second for the time you spend working on the tasks. You are free to stop working at any point during the competition though. You will NOT learn how many tasks you or your opponent has completed correctly during the competition. Nonetheless, the more tasks you complete correctly, the more likely you are to win in each round. The winner of each round is determined according to the same procedure as well.

\section{Your Probability to win \\ $=\frac{\text { total number of tasks completed correctly by you }}{\text { total number of tasks completed by correctly you and your competitor }}$}

You will be informed who the winner is at the end of each round.

At the end of round 2, if you have won (or lost) both rounds, you have won (or lost) the prize. There is no need to compete in the third round. You will still receive the full initial endowment AUD 3 for that round, as you will not spend any time working on the task.

However, if you and your competitor each have won one round after two rounds, you will need to compete in a third round to break the tie. The competition in the third round works the same as in the second round and the winner of the third round receives the prize.

\section{Your earnings}

Your payment in Part 2 will be calculated as the following:

If you win:

Your earnings $=$ prize $(A U D 20)+$ total endowment you kept in the last two rounds

If you lose:

Your earnings $=0+$ total endowment you kept in the last two rounds

After everyone in this room has finished the competition, you will need to answer a few more questions to finish the experiment. All the information you provide in this questionnaire, as well as your performance data in the experiment will only be used for statistical analysis and will be kept anonymous and strictly confidential. 
At the end of this session, your performance and your competitor's performance in every competition, as well as your payoff will be displayed to you.

To make sure you understand the instructions clearly, you will be asked to answer a few questions before we start this part of the experiment.

\section{$\underline{\text { Part } 2 \text { (for PastInfo \& PastWinUninformative treatments) }}$}

\section{Matching}

In this part, the computer will rank all the participants in this session according to the number of tasks completed correctly in Part 1 . Then it will match the two participants with the closest ranks into a pair. For instance, a participant with rank 1 will be paired with a participant with rank 2 , and a participant with rank 3 will be paired with the one in rank 4, etc.

The ranking and pairing assignments remain anonymous throughout the entire experiment. You will not be informed about the identity of the participant in this room you have been paired with. You will also not be able to learn your actual rank or the rank of anyone else. All you should keep in mind is that your opponent has the closest rank to you (based on performance records from Part 1).

\section{Competition}

In this part, the competition between you and your newly paired competitor consists of a maximum of three independent rounds. Whoever wins two out of the three rounds first wins the competition and will be awarded a prize of AUD 20.

The competition in the first two rounds follows the same procedure as the competition in Part 1: both you and your competitor will work simultaneously and independently for a maximum of 10 minutes on the same string-reversion task. For each of these two rounds, you are endowed with AUD 3. As soon as you begin to reverse the strings, your endowment starts depleting. You pay AUD 0.005 (i.e., half a cent) per second for the time you spend working on the tasks. You are free to stop working at any point during the competition though. [PastInfo: You will NOT learn how many tasks you or your opponent has completed during the competition.] Nonetheless, the more tasks you complete correctly, the more likely you are to win in each round. The winner of each round is determined according to the same procedure as well.

$$
\begin{aligned}
& \text { Your Probability to win } \\
& =\frac{\text { total number of tasks completed correctly by you }}{\text { total number of tasks completed by correctly you and your competitor }}
\end{aligned}
$$

You will be informed who the winner is at the end of each round.

At the end of round 2, if you have won (or lost) both rounds, you have won (or lost) the prize. There is no need to compete in the third round. However, if you and your competitor each have 
won one round after two rounds, you will enter a third round in which the computer will randomly draw a winner and the winner of the third round receives the prize.

You could imagine the random draw process in the third round as the following: the computer will first randomly assign you and your opponent to odd and even numbers, respectively. And then the computer will throw a rolling die (with numbers $1,2,3,4,5,6$ on each side of the dice). If the number showing up on the die is an odd number (either 1 , or 3, or 5 ), then who has been assigned to odd numbers will win round 3; if the number showing up on the dice is an even number (either 2 , or 4 , or 6 ), then who has been assigned to even numbers will win round 3. The winner in this round will be awarded the prize.

\section{Your earnings}

Your payment in Part 2 will be calculated as the following:

If you win:

Your earnings $=$ prize $(A U D 20)+$ total endowment you kept in the first two rounds

If you lose:

Your earnings $=0+$ total endowment you kept in the first two rounds

After everyone in this room has finished the competition, you will need to answer a few more questions to finish the experiment. All the information you provide in this questionnaire, as well as your performance data in the experiment will only be used for statistical analysis and will be kept anonymous and strictly confidential.

At the end of this session, your performance and your competitor's performance in every competition, as well as your payoff will be displayed to you.

To make sure you understand the instructions clearly, you will be asked to answer a few questions before we start this part of the experiment. 


\section{F.3 Instructions for backward-induction games}

You have finished the main part of the experiment! We will ask you to answer a few more questions, and you are able to make up to $\$ 4$ if you answer all the questions correctly.

Imagine you will play four games (similar to the following one) against the computer. For each game you win, you will receive one dollar. You will have 1 minute for each game. By the end of 1 minute, if you fail to choose, the next game will be shown to you.

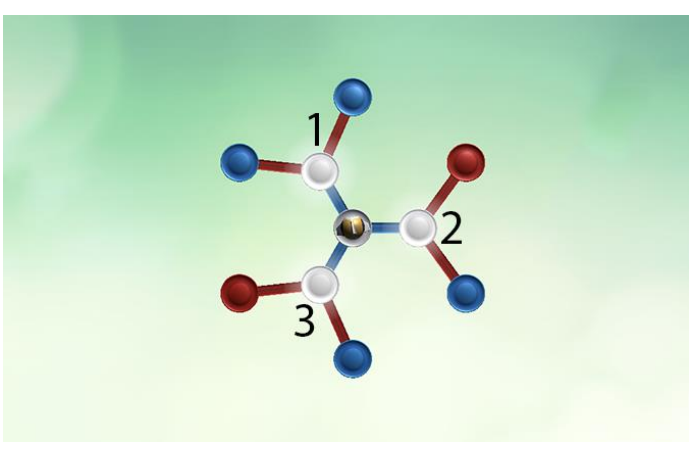

You are the first mover. You and the computer move the Robotoken alternately. Please keep in mind that the computer will always play optimally. This means it will take the best move trying to beat you.

You win a game if the Robotoken ends on a blue node. The computer wins if the Robotoken ends on a red node. You need to decide which first move to make in order to ensure you will win. In this example, you have three choices, 1, 2, 3 for you first move. Your correct choice should be 1. We will walk through this together.

You start in the middle and make the first move. By moving to option 1, this gives the computer the choice of moving left or right, both times ending on a blue node, you will always win if you choose 1 . If you were to choose option 2, the computer would then move to the left, meaning that the Robotoken ends on red and you will lose the game. If you were to choose option 3, the computer is going to move to the right, meaning that the Robotoken again ends on red. Therefore, the only possible move to ensure you win, is option 1 . 


\section{F.4 Four Games of backward induction}

Figure 10: Games of backward inductions with 1 step (top left), 2 steps (top right), 3 steps (bottom left), and 4 steps (bottom right) of backward induction. In each game, only one of the four first choices ensures a win.
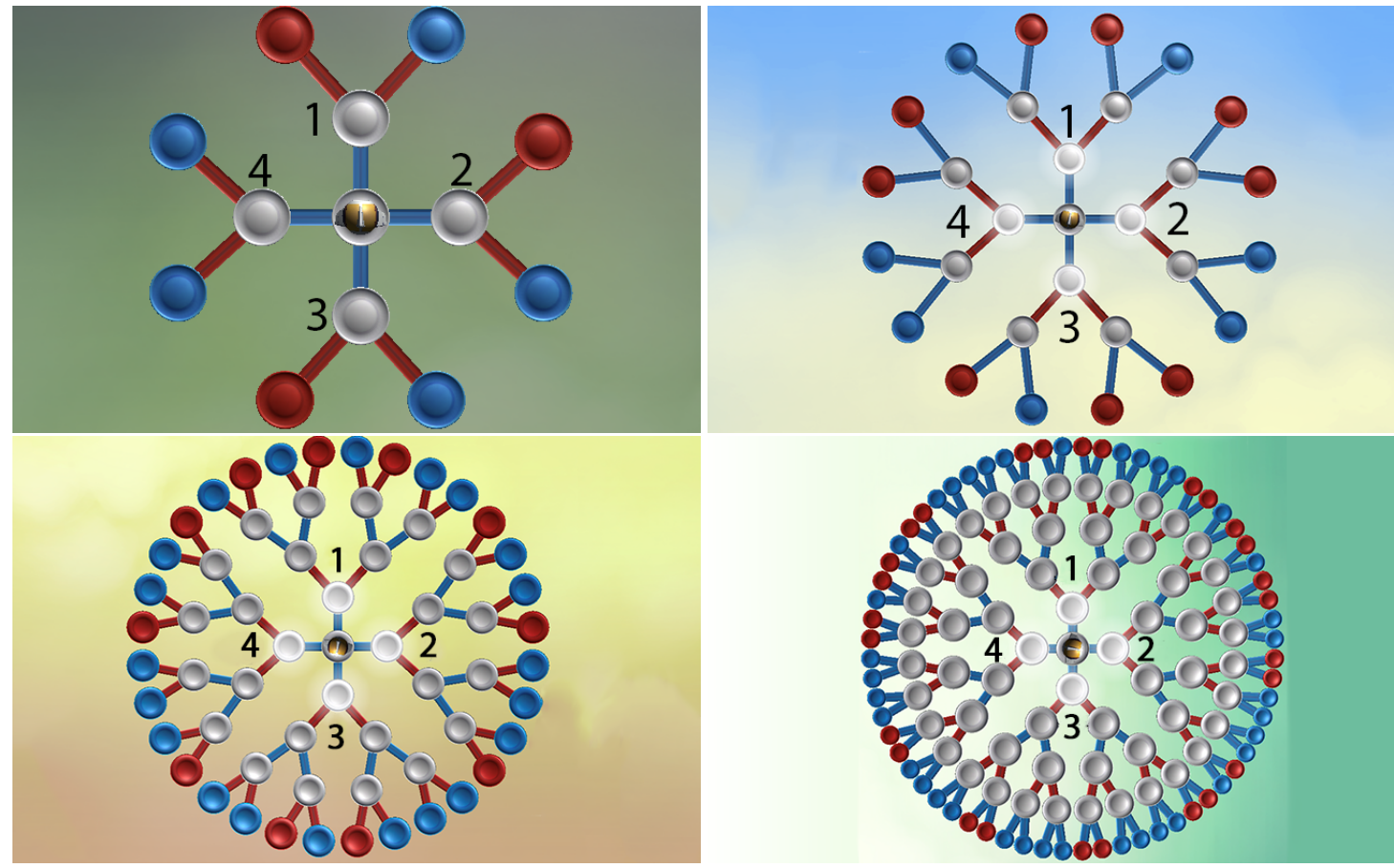